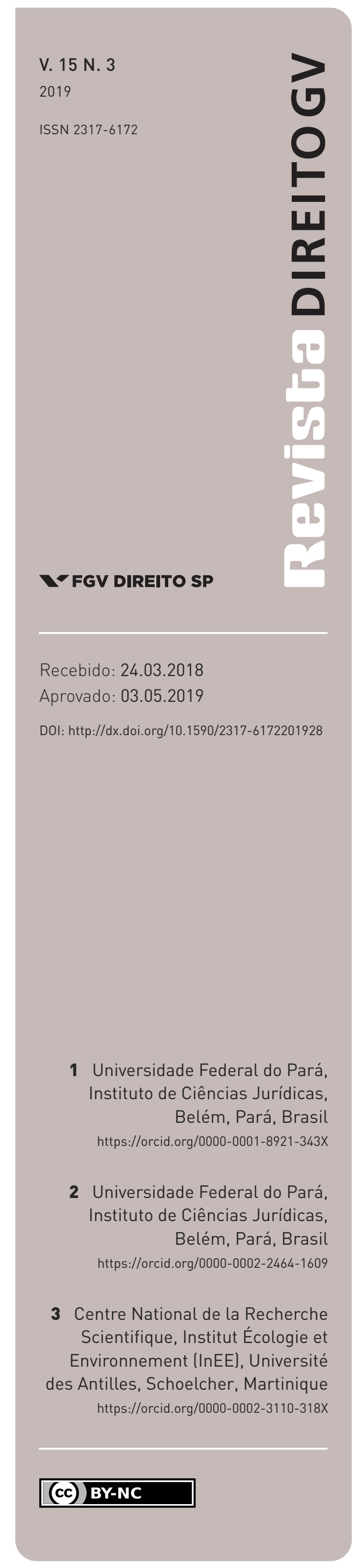

\section{ICMS Ecológico e desmatamento nos municípios prioritários do estado do Pará}

\author{
ECOLOGICAL ICMS AND DEFORESTATION IN PARÁ'S PRIORITY MUNICIPALITIES \\ Lise Tupiassu', Luiz Paulo de Sousa Leão Fadel² \\ e Jean-Raphaël Gros-Désormeaux ${ }^{3}$
}

\title{
Resumo
}

O ICMS Ecológico consiste no dimensionamento, segundo critérios ambientais, de parte dos repasses da parcela do Imposto sobre Circulação de Mercadorias e Serviços que cabe aos municípios. A política se presta à compensação e incentivo de ações favoráveis ao meio ambiente e foi introduzida no Pará com o objetivo explícito de contribuir para a redução das altas taxas de desmatamento, a partir do fomento à atuação municipal nesse propósito. Este estudo pretende verificar se os efeitos redistributivos iniciais operados pela política ocorreram em consonância com a finalidade almejada. Realizou-se análise da destinação dos recursos recebidos em razão da política, dos gastos municipais com gestão ambiental e da ingerência territorial municipal para compreender o impacto da introdução do critério ecológico de repartição sobre os municípios com altas taxas de desmatamento incluídos na Lista de Municípios Prioritários do Ministério do Meio Ambiente. Os resultados indicam que os municípios prioritários paraenses foram beneficiados com a introdução do ICMS Ecológico no estado sem que a política tenha implicado maior engajamento municipal no combate ao desmatamento. Conclui-se que houve certa incoerência entre os efeitos redistributivos operados pelos ICMS Ecológico paraense e o objetivo de redução do desmatamento, bem como com a base teórica da política.

\section{Palavras-chave}

ICMS Ecológico; municípios prioritários; gestão ambiental; desmatamento; Amazônia.

\begin{abstract}
The Ecological ICMS consists of the resizing, according to environmental criteria, of part of the monetary transfers of the ICMS (State Tax on Circulation of Goods and Services) belonging to municipalities. The policy's objective is to compensate and incentivize environmentally beneficial actions. It was introduced in Pará with the explicit purpose of contributing to the reduction of high rates of deforestation through the promotion of municipal action. This study intends to verify if the initial redistributive effects operated by the policy occurred in coherence with its intended purpose. It analyses the destination of resources received due to the policy, municipal expenditures with environmental management, and municipal territorial power to understand the impact of introducing the environmental criteria on municipalities with high rates of deforestation, which are included in the List of Priority Municipalities of the Ministry of Environment. The analysis indicates that the priority municipalities benefited from the introduction of the Ecological ICMS in the State, without increasing its participation in the fight against deforestation. It was concluded that there was some inconsistency between the redistributive effects operated by ICMS Ecological in Pará and the objective of reducing deforestation, as well as the policy's theoretical basis.
\end{abstract}

\section{Keywords}

Ecological ICMS; priority municipalities; environmental management; deforestation; Amazon Forest. 


\section{INTRODUÇÃO}

No presente momento histórico de reconhecimento e normatização dos direitos humanos, o meio ambiente equilibrado é consagrado como direito fundamental por diversos instrumentos internacionais e textos constitucionais. Na ordem constitucional brasileira, tal direito assume larga amplitude, por meio do enunciado do art. 225, caput, da Constituição de 1988 (BRASIL, 1988), que impõe aos poderes públicos a obrigação de adotar políticas que garantam a sua concretização (TUPIASSU, 2006, p. 57).

Nesse sentido, destaca-se, desde o final do século passado, a progressiva utilização de instrumentos tributários e financeiros para a implementação de políticas públicas de proteção ao meio ambiente e promoção de modelos de desenvolvimento sustentável (OCDE, 1989). O emprego desses mecanismos fundamenta-se em elementos de otimização econômica (PIGOU, 1929; BARDE, 1992), mas igualmente na constatação de que o poder de tributar somente é exercido legitimamente em um Estado de Direito na medida em que se destine a garantir a todos condições de gozo de direitos fundamentais (TORRES, 2005). Deve-se, portanto, conformar a atividade tributária - e financeira -, para que garanta a efetivação de direitos fundamentais, como o meio ambiente ecologicamente equilibrado.

Assim, dentro de um Estado constituído sob o modelo federativo, como o Brasil, a utilização de instrumentos econômicos e financeiros em políticas ambientais deve conformar-se com as competências compartilhadas constitucionalmente estabelecidas para todos os entes federativos, como também com os ditames do federalismo fiscal.

Nesse contexto, destaca-se o ICMS Verde ou Ecológico, o qual consiste no dimensionamento, segundo critérios ecológicos, do repasse aos municípios da parcela que lhes cabe da arrecadação do Imposto sobre Circulação de Mercadorias e Serviços (ICMS), imposto de competência estadual incidente sobre a circulação jurídica de mercadorias e a prestação de serviços de comunicação e de transporte interestadual e intermunicipal.

O estado do Pará incorporou a política por meio da Lei Estadual n. 7.638, de 12 de julho de 2012, com a finalidade de promover a justiça fiscal entre os entes municipais, de modo a compensar aqueles que adotem condutas compatíveis com a defesa do meio ambiente, além de incentivar os municípios a contribuir com a redução do desmatamento no estado, por meio do fomento a atividades sustentáveis (PARÁ, 2009).

Em que se pese o pouco tempo decorrido desde sua introdução, pretende-se examinar a coerência entre os efeitos redistributivos iniciais da política no estado do Pará e seus fundamentos teóricos e finalidades declaradas.

O recorte metodológico operou-se com o estudo restrito aos municípios paraenses integrantes da Lista de Municípios Prioritários do Ministério do Meio Ambiente (MMA), cujos territórios estão submetidos a intensas medidas de monitoramento e controle ambiental por parte do governo federal, com específicas condições administrativas e econômicas. Trata-se de grupo diretamente relacionado à finalidade de controlar e reduzir o desmatamento no Estado, por meio do engajamento efetivo dos entes municipais. 
Em função das altas taxas de desmatamento registradas nesses municípios, deveriam eles receber menor volume de repasses financeiros sob a nova sistemática de repartição de receitas, considerada a dupla função (compensatória e incentivadora) do ICMS Ecológico e o objetivo assumido na experiência paraense de combate ao desmatamento por meio do fomento à participação dos entes municipais.

Na hipótese, porém, de terem sido tais municípios beneficiados com a introdução da política, este estudo buscou apurar seu engajamento no combate ao desmatamento a partir da análise da aplicação em gestão ambiental dos recursos orçamentários geridos por esses mesmos municípios. Por fim, realizou-se a investigação das possibilidades de atuação municipal no combate ao desmatamento em espaços territoriais sob gestão territorial e fiscalização ambiental do estado-membro e da União, a partir do estudo dos casos dos municípios de Altamira e São Félix do Xingu.

O desenvolvimento do trabalho se inicia com uma breve caracterização do ICMS Ecológico, a partir de seus fundamentos teóricos e base constitucional. No segundo momento, será abordado o processo de adoção da política pelo estado do Pará, com análise dos instrumentos normativos que lhe deram forma. Na terceira seção, tratar-se-á da Lista de Municípios Prioritários e será esmiuçada a relação da hipótese inicial com a base teórica da política, bem como o tratamento financeiro por eles recebido desde a introdução da política, com base em recente pesquisa sobre a temática. Em seguida, passar-se-á à apresentação dos procedimentos metodológicos e dos resultados obtidos com a pesquisa de dados, analisando-se, nas seções que seguem, a destinação dos repasses financeiros e a atuação municipal no combate ao desmatamento e, por fim, as possibilidades e os óbices à atuação dos municípios de Altamira e São Félix do Xingu no combate ao desmatamento em espaços sob gestão territorial e fiscalização ambiental do estado-membro e da União.

\section{CARACTERIZAÇÃo do ICMS Ecológico}

No estado federativo brasileiro, a distribuição de competências delineada pela Constituição de 1988 dá ênfase ao federalismo cooperativo, ao atribuir extenso rol de competências legislativas concorrentes (art. 24) e competências materiais comuns aos entes federativos (art. 23) (BRASIL, 1988).

No que se refere à competência comum em matéria ambiental, se reconhece um verdadeiro dever fundamental de cooperação entre os entes federativos para a concretização do direito ao meio ambiente ecologicamente equilibrado (SARLET, MACHADO e FENSTERSEIFER, 2015, p. 71-72).

Há uma interdependência entre as esferas governamentais, cujo reconhecimento é essencial para a eficácia das ações de defesa do meio ambiente. No Estado brasileiro, estruturado em uma federação de três níveis, a atuação estatal nessa área demanda uma intensa cooperação intergovernamental, na qual se reconhece o reposicionamento do município como um 
ator fundamental, tanto na defesa do ambiente na dimensão do interesse local quanto em estratégias regionais e nacionais. Em vista disso, a União e os estados-membros necessitam ganhar sua adesão voluntária para que possam contribuir para a implementação de iniciativas da esfera federal e estadual (NEVES, 2014).

Por outro lado, a atribuição de competências ambientais aos municípios demanda a construção de capacidades que possibilitem o desempenho das tarefas que lhes foram conferidas pelo texto constitucional, já que o exercício da autonomia local está condicionado à existência dos recursos e estruturas - sobretudo, de fontes de financiamento - indispensáveis para o exercício de seu mandato ambiental.

Nessa esteira, a dimensão cooperativa prepondera, igualmente, no aspecto fiscal e financeiro, sobretudo pela importância conferida às transferências governamentais, instrumentos de efetivação da autonomia financeira dos entes e de promoção do equilíbrio federativo (CONTI, 2001, p. 24).

O ICMS Ecológico ou Verde é um mecanismo que se insere no desenho cooperativo do federalismo fiscal brasileiro, uma vez que se utiliza de transferências intergovernamentais como instrumento de política ambiental, redimensionando repasses financeiros segundo critérios ecológicos.

Conforme disposição do art. 158, inciso IV, da Constituição Federal, 25\% da arrecadação de ICMS pelos estados-membros deve ser repassada aos municípios da seguinte maneira: no mínimo três quartos, segundo o critério do valor adicionado fiscal; e até um quarto, conforme as disposições da legislação estadual (BRASIL, 1988).

O valor adicionado fiscal é indicador de natureza contábil, consistente, em síntese, na diferença entre os valores das operações de compra e venda sujeitas à incidência de ICMS no município. Desse modo, a distribuição de receitas segundo tal critério privilegia, em regra, os municípios que mais contribuem para a arrecadação de ICMS, os quais, comumente, são os que apresentam maior população e maior grau de desenvolvimento econômico e, por conseguinte, também são grandes geradores de externalidades negativas. Por sua vez, os municípios que têm restrições ambientais ao seu desenvolvimento econômico - decorrentes, por exemplo, da delimitação de espaços protegidos - recebem menor volume de transferências financeiras, apesar de produzirem externalidades positivas (SCAFF e TUPIASSU, 2004, p. 734).

Embora de difícil definição (BAUMOL e OATES, 1988, p. 14 e ss.), o termo "externalidade" denota efeitos, negativos ou positivos, produzidos por agentes econômicos, cujos custos não são objeto de avaliação ou compensação pelo mercado (MARSHALL, 1920; PIGOU, 1929; TUPIASSU, 2010). No que toca à situação apresentada, os municípios que têm parcela de seu território afetada à preservação ambiental geram externalidades positivas - como a garantia de diversidade genética de espécies animais e vegetais, estabilização do clima e manutenção dos modos de vida de populações tradicionais -, sem que aufiram benefícios financeiros com sua conduta. 
Em vista disso, surge a necessidade de corrigir tais falhas do mercado a partir da intervenção estatal (PIGOU, 1929; LÉVÊQUE, 1999), o que pode se dar mediante a aplicação do princípio do poluidor pagador, por meio do qual se busca imputar ao poluidor os custos sociais decorrentes da degradação ambiental associada à sua conduta, realizando a internalização de custos externos (externalidades negativas) que, caso contrário, seriam arcados pela coletividade (MILARÉ, 2015). Desse modo, os custos de medidas de prevenção e de controle da poluição por parte das autoridades estatais recaem sobre o poluidor e refletem nos custos dos bens e serviços por ele produzidos ou consumidos (OCDE, 1972). Por outro lado, pode-se, em vez de tentar coibir a produção de externalidades negativas, recompensar e incentivar condutas ambientalmente virtuosas, mediante aporte de recursos a agentes responsáveis pela produção e pela oferta de serviços ou bens ambientais (WUNDER, 2005).

Nesse contexto, com base na previsão constitucional de distribuição de um quarto da cota-parte de ICMS que pertence aos municípios segundo critérios previstos na legislação estadual, surgiu o ICMS Verde ou Ecológico, a partir da iniciativa de diversos estados-membros, que passaram a adotar critérios ecológicos de repartição de receita.

A política foi concebida com uma finalidade marcadamente compensatória - como se verificou no estado do Paraná, o primeiro a adotá-la -, uma vez que seu surgimento decorreu das demandas de municípios que abrigavam áreas especialmente protegidas, como modo de compensá-los pelas restrições econômicas decorrentes da afetação de parcela de seu território à preservação ambiental (LOUREIRO, 2002). Contudo, passou-se com o tempo a reconhecer importante viés incentivador de condutas dos entes municipais, com a adoção de critérios afetos às searas ambiental e social (OLIVEIRA, 2014, p. 80).

Desse modo, nota-se que o ICMS Verde tem duas dimensões: uma compensatória, como forma de corrigir o desequilíbrio de oportunidades de desenvolvimento econômico entre os municípios, decorrente de restrições de natureza ambiental; e outra, incentivadora, sob a qual se busca induzir os entes municipais a se adequar aos critérios de repartição de receitas definidos pela política (TUPIASSU, GROS-DÉSORMEAUX e FADEL, 2018, p. 73).

Trata-se de forte instrumento econômico para a concretização da finalidade constitucional de preservação ambiental, promovendo justiça fiscal e influenciando as condutas dos entes municipais, que naturalmente buscam obter aumentos de receita ao se adequar aos critérios legais. É forma de intervenção positiva do Estado, como fator de regulação não coercitiva, assemelhando-se a um incentivo fiscal intergovernamental (TUPIASSU, 2006, p. 195).

Ainda, é método que pode ser adotado pelos estados-membros para induzir os entes municipais a se engajar no exercício da competência comum de defesa e promoção do meio ambiente equilibrado. Como visto, há uma nítida interdependência entre as esferas políticas para o desempenho do seu mandato ambiental, e, com a ampliação das competências ambientais dos entes municipais a partir da Constituição de 1988, sua contribuição à concretização do dever estatal fundamental de proteção do meio ambiente deve ser incentivada. 
Por fim, há a possibilidade de se utilizar o ICMS Verde como um incentivo à construção das capacidades essenciais à concretização da agenda ambiental municipal. Ao buscar se adequar aos critérios ambientais de repartição de receitas, é natural que os municípios envolvidos passem a despender maiores esforços na defesa dos bens ambientais. Desse modo, um dos resultados esperados é um aumento na destinação de recursos à área ambiental. Nessa perspectiva, a política vem sendo adotada de forma crescente pelos mais diversos estados do Brasil, buscando atingir diferentes objetivos no plano socioambiental.

\section{O ICMS Verde no eSTAdo do PARÁ}

Desde sua promulgação em 1989, a Constituição do Estado do Pará já previa, em seu art. 225, tratamento especial aos municípios que tenham parte de seus territórios afetada por unidades de conservação em relação aos créditos das parcelas de receita oriunda da arrecadação do ICMS (PARÁ, 1989). No entanto, somente após a inclusão do ICMS Verde como ação prioritária no Plano de Prevenção, Controle e Alternativas ao Desmatamento do Estado do Pará (PPCAD-PA), em 2009, é que se buscou regulamentar o dispositivo constitucional, o que resultou na aprovação da Lei Estadual n. 7.638/2012, que incluiu critério ecológico de repartição de receitas do ICMS entre os municípios ao alterar as disposições da Lei Estadual n. 5.645, de 11 de janeiro de 1991 (TUPIASSU e HABER, 2014, p. 299).

Segundo dispôs a Lei n. 7.638/2012, a introdução do critério ecológico ocorreu de forma gradual, com a diminuição anual e sucessiva do critério igualitário de distribuição - segundo o qual cada município receberia idêntico valor de repasse (PARÁ, 2012). Anteriormente, o critério igualitário equivalia a 15\% do total repassado aos municípios; a partir de 2014, o critério igualitário passou a ser reduzido anualmente até 2017, com equivalente aumento do critério ecológico, de modo que a divisão se estabilizou em 7\% para o critério igualitário e $8 \%$ para o critério ecológico (PARÁ, 2013). ${ }^{1}$

A Lei n. 7.638/2012 previu, em seu art. $2^{\circ}$, que seriam beneficiados pelo critério ecológico os municípios cujo território abrigasse unidades de conservação e outras áreas protegidas, desde que participassem da implementação e gestão dessas áreas. Ademais, a lei estadual

1 Conforme dispõem os incisos do art. $3^{\circ}$ do Decreto n. 775/2013, o cálculo e o repasse da parcela da arrecadação do ICMS distribuída sob o ICMS Verde seguiu os seguintes percentuais e cronograma: 2\% referentes ao ano-base 2012, calculados em 2013 e repassados em 2014; 4\% referentes ao ano-base 2013, calculados em 2014 e repassados em 2015; 6\% referentes ao ano-base 2014, calculados em 2015 e repassados em 2016; 8\% referentes ao ano-base 2015, calculados em 2016 e repassados em 2017 (PARÁ, 2013). Assim, as etapas da divisão de receitas segundo o critério ecológico se verificam em momentos distintos: os dados referentes aos indicadores ambientais que compõem o critério ecológico são aferidos em determinado ano; no ano seguinte, é efetuado o cálculo dos índices de repasse de cada município; por fim, no ano subsequente os valores são repassados aos entes municipais. 
estabeleceu, em seu art. $3^{\circ}$, que a fruição do tratamento especial dependeria da manutenção de Sistema Municipal do Meio Ambiente, de natureza participativa e que preenchesse certos requisitos mínimos (PARÁ, 2012). ${ }^{2}$

No entanto, o Decreto n. 775, de 26 de junho de 2013, que regulamentou a referida lei estadual, incluiu outros dois fatores: o índice de cobertura vegetal e redução das taxas de desmatamento, e o percentual de inscrição da área do município inscrito no Cadastro Ambiental Rural (CAR). Em vista disso, a composição do critério ecológico assumiu a seguinte configuração: (1) 25\%, conforme a porcentagem do território municipal ocupado por áreas protegidas e de uso especial; (2) 25\%, ante a existência de um estoque mínimo de cobertura vegetal e a redução do desmatamento nos municípios; (3) 50\%, considerando a porcentagem da área cadastrável do município inserida no CAR (PARÁ, 2013).

A partir de 2017, o critério ecológico foi novamente alterado por meio da Portaria Semas/PA de n. 1.272, de 21 de julho de 2016, seguida do Decreto Estadual n. 1.696, de 7 de fevereiro de 2017. A finalidade declarada dessa alteração foi inserir uma dimensão qualitativa e inclusiva na agenda do ICMS Verde (PARÁ, 2016). A gestão ambiental municipal passou a compor o critério ecológico, como um novo indicador. Em vista disso, o valor de repasse passou a ser calculado levando-se em conta quatro fatores, de pesos distintos e atualizados anualmente (PARÁ, 2017). ${ }^{3}$

Em vista da configuração assumida pelo ICMS Verde no estado do Pará, bem como dos objetivos declarados por ocasião de sua instituição, percebe-se que sua finalidade principal é reduzir e controlar o desmatamento nos municípios paraenses. Nessa perspectiva, o Pará não seguiu a tendência dos demais estados brasileiros de incluir critérios com aspectos socioambientais, optando por privilegiar especialmente os municípios que detêm áreas ambientalmente

O Sistema Municipal deve ser composto, no mínimo, por: a) Conselho Municipal do Meio Ambiente, de caráter deliberativo e composição socialmente paritária; b) Fundo Municipal do Meio Ambiente; c) órgão executor da Política Municipal do Meio Ambiente, dotado de recursos humanos, materiais e financeiros adequados e suficientes para exercer suas funções, em especial, a implantação do processo de planejamento e o Plano Municipal do Meio Ambiente; d) demais instrumentos de política pública e participativa necessários à plena execução da Política Municipal do Meio Ambiente (PARÁ, 2012).

3 Conforme a Portaria Semas/PA n. 1.310/17, os fatores e pesos são os seguintes, em relação ao ano de 2018: Fator 1, denominado de Regularização Ambiental, composto pelos indicadores CAR, Área de Preservação Permanente (APP), Reserva Legal (RL) e a Área Degradada (AD), de peso de 44,565\%; Fator 2, denominado de Gestão Territorial, composto pelos indicadores Áreas Protegidas de Uso Restrito, Áreas Protegidas de Uso Sustentável, Desflorestamento e Desflorestamento em Áreas Protegidas, com peso de 29,871\%; Fator 3, denominado de Estoque Florestal, formado por um único indicador (Remanescente Florestal), apresentando um peso de 14,223\%\%; Fator 4, denominado de Fortalecimento da Gestão Ambiental Municipal, também composto por um único indicador (Capacidade de Exercício da Gestão Ambiental), com peso de $11,341 \%$ (PARÁ, 2017). 
protegidas. Ademais, há a intenção de incentivar a implementação de uma gestão ambiental local avançada, com uma estrutura completa e qualitativamente satisfatória, uma vez que se exige a estruturação de um Sistema Municipal de Meio Ambiente (TUPIASSU e OLIVEIRA, 2016, p. 286-287).

Portanto, por meio do dimensionamento de transferências entre os entes federativos mecanismo inerente ao federalismo cooperativo -, a política busca engajar os municípios no combate ao desmatamento por meio de incentivos financeiros estabelecidos pelo ente estadual, reconhecendo a importância de sua participação para a efetividade das políticas ambientais. Ademais, pretende viabilizar a autonomia local no que se refere ao exercício da agenda ambiental municipal, ao incentivar a construção de capacidade e o emprego de recursos sobretudo financeiros - nessa área.

\section{MUNICÍPIOS PRIORITÁRIOS E ICMS VERDE}

A instituição da Lista de Municípios Prioritários decorreu do Plano de Ação de Prevenção e Controle do Desmatamento na Amazônia (PPCDAM), iniciativa lançada em 2004 com o objetivo de reduzir, de maneira contínua e consistente, o desmatamento amazônico, bem como criar condições para se estabelecer um modelo de desenvolvimento sustentável na região (BRASIL, 2017a).

A partir de 2008, com a segunda fase do plano, houve uma redução drástica do desmatamento amazônico, notadamente em decorrência de ações de monitoramento e controle (WHATELY e CAMPANILI, 2013, p. 18). Entre as medidas adotadas naquele momento, destaca-se o Decreto n. 6.321, de 21 de dezembro de 2007, que institui lista de municípios, selecionados em razão das altas taxas de desmatamento registradas, cujos territórios são submetidos a medidas de integração e aperfeiçoamento das ações de monitoramento e controle de órgãos federais, de ordenamento fundiário e territorial e de incentivo a atividades econômicas ambientalmente sustentáveis (BRASIL, 2017b), bem como a restrições administrativas e econômicas significativas. ${ }^{4}$

As medidas restritivas recaem diretamente sobre os responsáveis pelos imóveis rurais e não sobre as administrações municipais. Segundo a estratégia adotada, os municípios assumem

4 Entre as quais se destacam: proibição de emissão de novas autorizações de desmatamento em dimensão superior a 5 hectares; possibilidade de recadastramento de imóveis rurais pelo Instituto Nacional de Colonização e Reforma Agrária (Incra); embargo de áreas desmatadas ilegalmente; intensificação da fiscalização; publicação pelo Instituto Brasileiro do Meio Ambiente e dos Recursos Naturais Renováveis (Ibama) da lista de imóveis com cobertura vegetal monitorada/embargados; proibição de concessão de crédito por agências oficiais para atividades agropecuárias ou florestais em imóvel rural que descumpra embargo (NEVES, 2015, p. 7). 
apenas a função de unidades espaciais, de modo a identificar as áreas que devem ser submetidas à ação federal, sem que se tenha buscado integrá-los à estratégia de atuação enquanto agentes políticos. No entanto, por meio da promoção de coalizões locais, alguns municípios - como Paragominas/PA - construíram sua capacidade de contribuição ao combate ao desmatamento, apesar de serem tratados como meros espaços onde a política seria executada (NEVES e WHATELY, 2016).

Os critérios para inclusão na lista, a qual é atualizada anualmente mediante portaria do MMA, são os seguintes: a) área total de floresta desmatada no território do município; b) área total de floresta desmatada nos últimos três anos; c) aumento da taxa de desmatamento em pelo menos três, dos últimos cinco anos (BRASIL, 2017b). Ademais, também são editados anualmente critérios para a saída da lista, os quais passam à categoria de municípios com processo de desmatamento sob controle e monitorado. Atualmente, 15 municípios do estado do Pará integram a lista. ${ }^{\mathbf{5}}$

Quanto ao tratamento que deve ser conferido aos municípios prioritários pelo ICMS Verde paraense, é necessário observar como tais entes se relacionam com os pressupostos inerentes à política, sobretudo em relação à sua dupla dimensão (compensatória e incentivadora).

Nesse sentido, como o processo de desflorestamento é mais acentuado em seus territórios, tornam-se grandes produtores de externalidades negativas - como a perda de biodiversidade, emissão de gases que intensificam o efeito estufa e o desalojamento de populações tradicionais -, o que deveria restringir a possibilidade de serem beneficiados com a função compensatória da política. Em vista disso, maior parcela de repasses deveria ser alocada aos entes municipais provedores de serviços ecossistêmicos e não a municípios com altas taxas de desmatamento, como os que integram a Lista de Municípios Prioritários (FERREIRA, 2016).

Por sua vez, quanto à dimensão incentivadora, os municípios prioritários somente poderiam aumentar suas receitas ao se adequar aos critérios ecológicos definidos, que deveriam ser suficientemente rígidos para garantir que fossem induzidos a se engajar no combate ao desmatamento e a utilizar os recursos financeiros recebidos em razão da política na concretização da agenda ambiental municipal. Caso contrário, com critérios brandos e incapazes de mensurar o seu esforço ambiental, não haveria incentivo ao esperado incremento da atuação

5 Quais sejam: São Félix do Xingu, Santa Maria das Barreiras, Rondon do Pará, Novo Repartimento, Novo Progresso, Cumaru do Norte e Altamira (incluídos pela Portaria MMA n. 28, de 24 de janeiro de 2008); Pacajá, Marabá e Itupiranga (Portaria MMA n. 102, de 24 de março de 2009); Moju (Portaria MMA n. 175, de 24 de maio de 2011); Senador José Porfírio e Anapu (Portaria MMA n. 323, de 28 de setembro de 2012); Itaituba e Portel (Portaria MMA n. 361, de 8 de setembro de 2017). Cumpre observar que, como a inclusão dos municípios de Itaituba e Portel é recente, optou-se por não os incluir na análise. 
dos entes municipais na defesa do meio ambiente. De início, portanto, os municípios prioritários deveriam ter sua participação na cota-parte da arrecadação do ICMS reduzida, em relação ao montante que receberiam sob a forma de repartição anterior, até que atingissem os indicadores ambientais exigidos, a partir de seu esforço ambiental (TUPIASSU, GROS-DÉSORMEAUX e FADEL, 2018, p. 77).

No entanto, não foi o que ocorreu, conforme concluiu análise detida do impacto financeiro da introdução da política em relação aos municípios prioritários. Ao comparar os valores recebidos pelos municípios prioritários desde 2014, quando se iniciou a implementação do critério ecológico, com o montante que seria transferido a esse grupo de municípios caso se mantivesse a forma anterior de repartição de receitas, verificou-se que, em geral, os municípios prioritários saíram beneficiados com o ICMS Verde (TUPIASSU, GROS-DÉSORMEAUX e FADEL, 2018). Nesse sentido, encontram-se os resultados constantes da Tabela 1 e Gráfico 1, referentes ao período de 2014 a 2016.

TABELA 1 - VALOR TOTAL (R\$) REPASSADO DESDE A INTRODUÇÃO DO CRITÉRIO ECOLÓGICO ( 20 I 4- 2 O I 6 ) E O MONTANTE QUE SERIA REPASSADO CASO NÃO HOUVESSE A INTRODUÇÃO DO CRITÉRIO ECOLÓGICO

\begin{tabular}{|c|c|c|c|c|c|}
\hline \multirow[b]{3}{*}{ MUNICÍPIOS } & \multirow{3}{*}{$\begin{array}{l}\text { TOTAL } \\
2014\end{array}$} & \multirow{3}{*}{$\begin{array}{l}\text { TOTAL } \\
2015\end{array}$} & \multirow{3}{*}{$\begin{array}{l}\text { TOTAL } \\
2016\end{array}$} & \multirow{3}{*}{$\begin{array}{l}\text { TOTAL } \\
\text { 2014-2016 }\end{array}$} & \multirow{3}{*}{$\begin{array}{l}\text { TOTAL } \\
\text { 2014-2016 } \\
\text { SEM O CRITÉRIO } \\
\text { ECOLÓGICO }\end{array}$} \\
\hline & & & & & \\
\hline & & & & & \\
\hline ALTAMIRA & $30.089 .436,51$ & $37.194 .083,26$ & $43.691 .389,46$ & $110.974 .909,23$ & $109.575 .831,94$ \\
\hline ANAPU & $4.712 .803,31$ & $6.036 .736,03$ & $6.845 .655,49$ & $17.595 .194,83$ & $16.031 .852,23$ \\
\hline CUMARU DO NORTE & $6.344 .158,30$ & $7.205 .136,55$ & $7.852 .369,53$ & $21.401 .664,38$ & $20.225 .019,66$ \\
\hline ITUPIRANGA & $5.256 .588,30$ & $6.815 .669,71$ & $8.053 .712,34$ & $20.125 .970,35$ & $19.151 .330,46$ \\
\hline MARABÁ & $85.918 .029,54$ & $95.614 .109,32$ & $110.738 .544,73$ & $292.270 .683,59$ & $291.444 .192,01$ \\
\hline MOJU & $9.063 .083,28$ & $12.657 .672,31$ & $13.892 .653,79$ & $35.613 .409,38$ & $35.502 .379,62$ \\
\hline NOVO PROGRESSO & $9.063 .083,28$ & $10.320 .871,27$ & $11.476 .540,09$ & $30.860 .494,64$ & $29.868 .127,33$ \\
\hline NOVO REPARTIMENTO & $8.700 .559,95$ & $11.099 .804,96$ & $13.288 .625,36$ & $33.088 .990,27$ & $32.321 .531,32$ \\
\hline
\end{tabular}

(continua) 


\begin{tabular}{|c|c|c|c|c|c|}
\hline MUNICÍPIOS & $\begin{array}{l}\text { TOTAL } \\
2014\end{array}$ & $\begin{array}{l}\text { TOTAL } \\
2015\end{array}$ & $\begin{array}{l}\text { TOTAL } \\
2016\end{array}$ & $\begin{array}{l}\text { TOTAL } \\
\text { 2014-2016 }\end{array}$ & $\begin{array}{l}\text { TOTAL } \\
\text { 2014-2016 } \\
\text { SEM O CRITÉRIO } \\
\text { ECOLÓGICO }\end{array}$ \\
\hline PACAJÁ & $5.981 .634,97$ & $7.399 .869,97$ & $8.859 .083,58$ & $22.240 .588,52$ & $21.883 .540,12$ \\
\hline RONDON DO PARÁ & $6.887 .943,30$ & $7.205 .136,55$ & $7.651 .026,73$ & $21.744 .106,58$ & $22.334 .971,89$ \\
\hline \multicolumn{6}{|l|}{ SANTA MARIA } \\
\hline DAS BARREIRAS & $5.256 .588,30$ & $6.036 .736,03$ & $6.644 .312,69$ & $17.937 .637,02$ & $17.667 .178,63$ \\
\hline SÃO FÉLIX DO XINGU & $19.032 .474,90$ & $22.589 .076,75$ & $24.966 .508,27$ & $66.588 .059,92$ & $64.345 .717,23$ \\
\hline $\begin{array}{l}\text { SENADOR JOSÉ } \\
\text { PORFÍRIO }\end{array}$ & $3.806 .494,98$ & $4.478 .868,67$ & $4.630 .884,59$ & $12.916 .248,24$ & $11.076 .558,40$ \\
\hline
\end{tabular}

Fonte: Tupiassu, Gros-Désormeaux e Fadel (2018).

GRÁFICO 1 - VARIAÇÃO EM PERCENTUAL ENTRE VALOR REPASSADO DESDE A INTRODUÇÃO DO CRITÉRIO ECOLÓGICO ( 20 I 4- 20 I 6 ) E O MONTANTE QUE SERIA REPASSADO CASO NÃO HOUVESSE A INTRODUÇÃO DO CRITÉRIO ECOLÓGICO, CONSIDERANDO O VALOR TOTAL DA COTA-PARTE DE CADA MUNICÍPIO

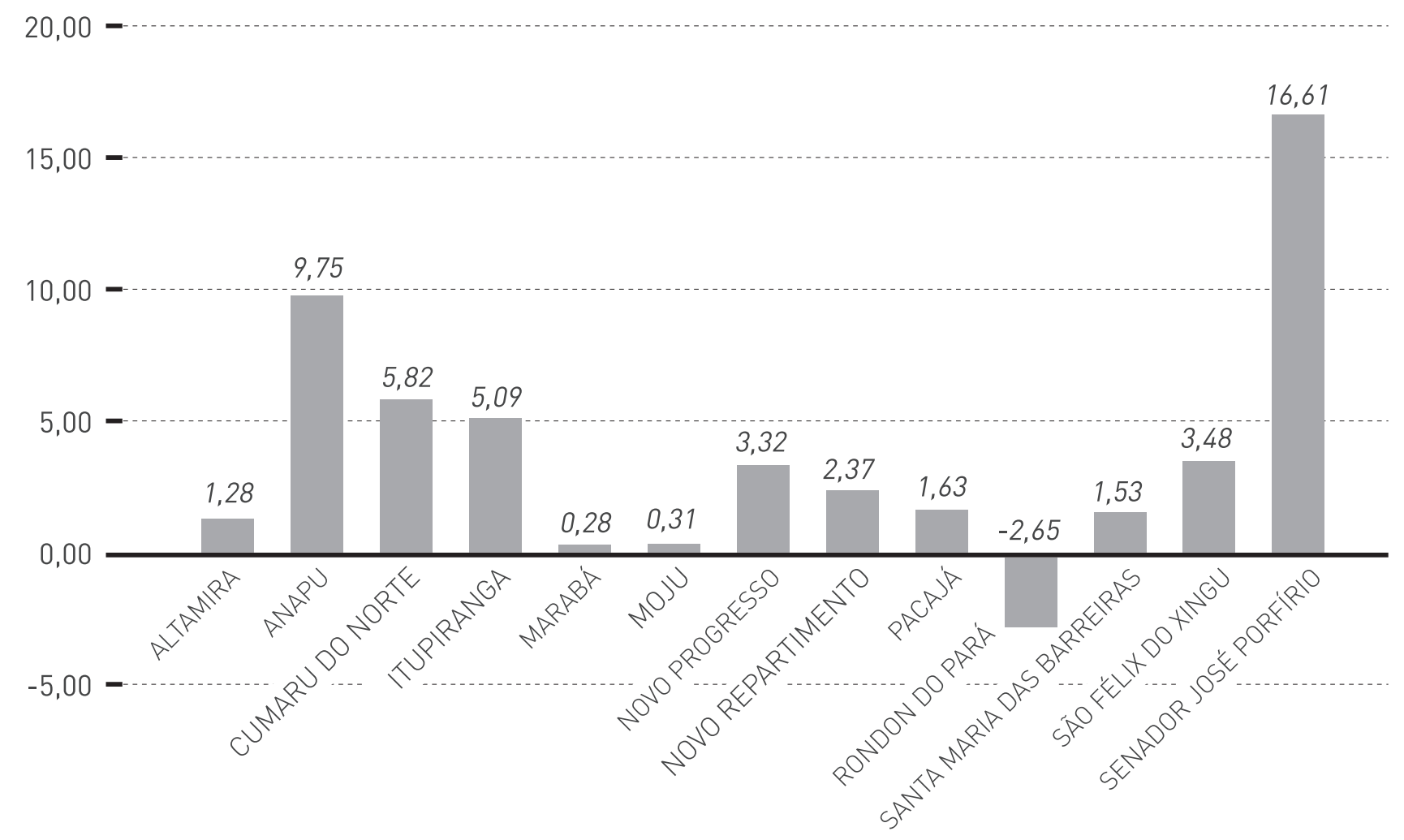

Fonte: Tupiassu, Gros-Désormeaux e Fadel (2018). 
Inclusive, com a alteração na composição do critério ecológico realizada pela Portaria Semas/PA n. 1.272/2016 e Decreto n. 1.696/2017, houve um incremento ainda maior de transferências financeiras aos municípios prioritários no ano de 2017 (TUPIASSU, GROS-DÉSORMEAUX e FADEL, 2018), conforme apontam a Tabela 2 e o Gráfico 2.

TABELA 2 - VALORES DE REPASSE (RS) PARA OS MUNICÍPIOS PRIORITÁRIOS NO ANO DE 20I7, SOB OS CRITÉRIOS IGUALITÁRIO E ECOLÓGICO, E OS VALORES QUE LHES SERIAM REPASSADOS SEM A INTRODUÇÃO DO CRITÉRIO ECOLÓGICO

\begin{tabular}{|c|c|c|c|c|}
\hline MUNICÍPIOS & $\begin{array}{l}2017 \text { - CRITÉRIOS } \\
\text { ECOLÓGICO }(8 \%) \\
\text { E IGUALITÁRIO (7\%) }\end{array}$ & IGUALITÁRIO (15\%) & 2017 - TOTAL & $\begin{array}{l}\text { 2017 - TOTAL } \\
\text { (SEM O CRITÉRIO } \\
\text { ECOLÓGICO) }\end{array}$ \\
\hline ALTAMIRA & $4.234 .358,52$ & $2.136 .576,63$ & $43.893 .830,35$ & $41.796 .048,46$ \\
\hline ANAPU & $2.222 .739,14$ & $2.136 .576,63$ & $6.358 .452,06$ & $6.272 .289,55$ \\
\hline CUMARU DO NORTE & $2.894 .250,97$ & $2.136 .576,63$ & $8.614 .676,99$ & $7.857 .002,65$ \\
\hline ITUPIRANGA & $2.483 .751,54$ & $2.136 .576,63$ & $8.614 .676,99$ & $8.267 .502,08$ \\
\hline MARABÁ & $2.727 .512,51$ & $2.136 .576,63$ & $123.887 .259,50$ & $123.296 .323,62$ \\
\hline MOJU & $2.222 .738,23$ & $2.136 .576,63$ & $12.306 .681,40$ & $12.220 .519,80$ \\
\hline NOVO PROGRESSO & $2.998 .196,09$ & $2.136 .576,63$ & $12.511 .792,77$ & $11.650 .173,31$ \\
\hline NOVO REPARTIMENTO & $2.656 .970,72$ & $2.136 .576,63$ & $13.332 .238,19$ & $12.811 .844,10$ \\
\hline PACAJÁ & $2.617 .613,53$ & $2.136 .576,63$ & $10.460 .679,20$ & $9.979 .642,30$ \\
\hline RONDON DO PARÁ & $2.222 .736,42$ & $2.136 .576,63$ & $9.024 .899,70$ & $8.938 .739,91$ \\
\hline \multicolumn{5}{|l|}{ SANTA MARIA } \\
\hline DAS BARREIRAS & $2.600 .700,48$ & $2.136 .576,63$ & $7.589 .120,20$ & $7.124 .996,35$ \\
\hline SÃO FÉLIX DO XINGU & $3.846 .243,32$ & $2.136 .576,63$ & $27.074 .699,10$ & $25.365 .032,41$ \\
\hline \multicolumn{5}{|l|}{ SENADOR JOSÉ } \\
\hline PORFÍRIO & $2.479 .595,32$ & $2.136 .576,63$ & $4.307 .338,49$ & $3.964 .319,80$ \\
\hline
\end{tabular}

Fonte: Tupiassu, Gros-Désormeaux e Fadel (2018). 
GRÁFICO 2 - VARIAÇÃO EM PERCENTUAL ENTRE VALOR ESTIMADO DE REPASSE PARA 2017 E O MONTANTE QUE SERIA REPASSADO CASO NÃO HOUVESSE A INTRODUÇÃO DO CRITÉRIO ECOLÓGICO, CONSIDERANDO O VALOR TOTAL DA COTA-PARTE DE CADA MUNICÍPIO

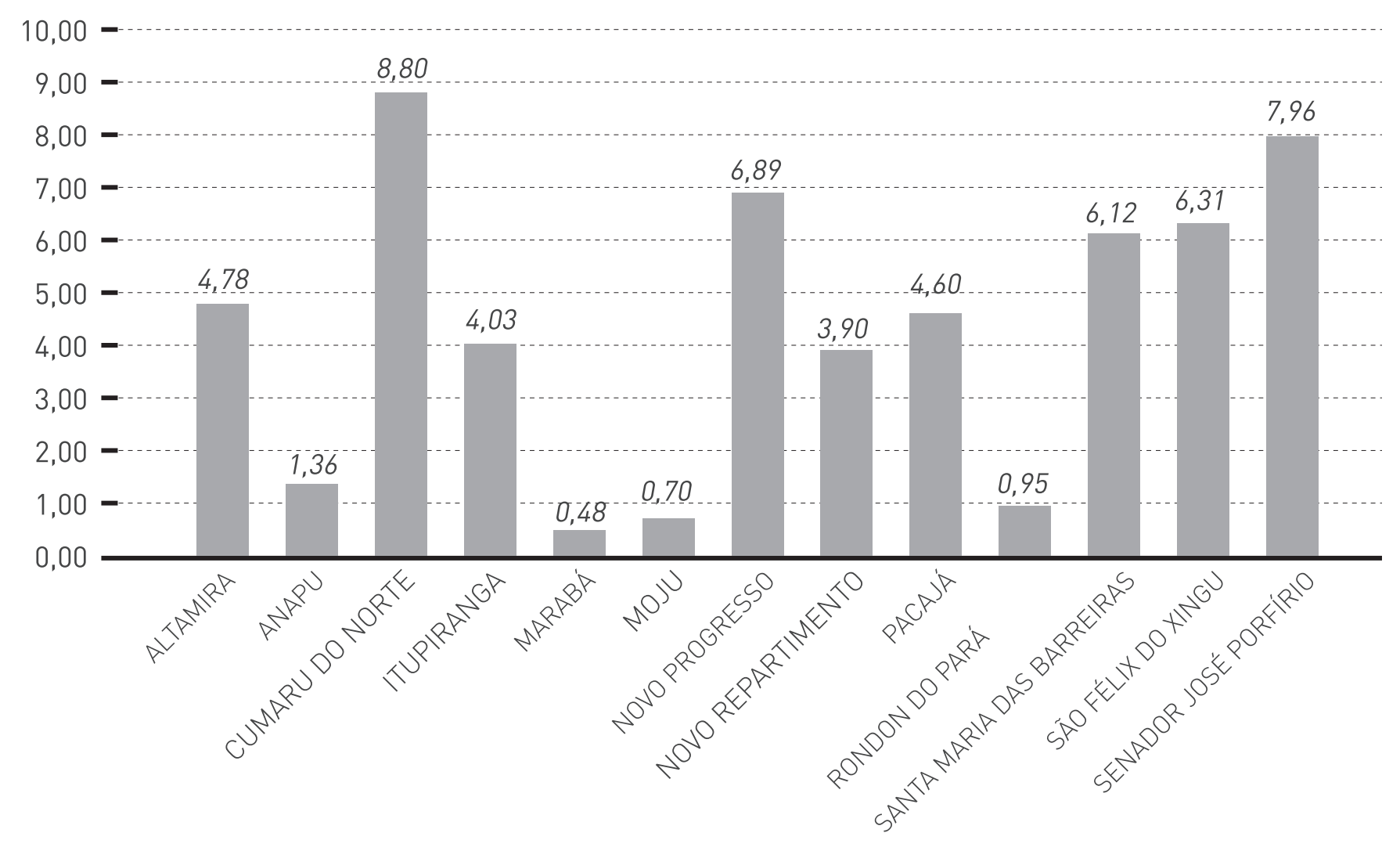

Fonte: Tupiassu, Gros-Désormeaux e Fadel (2018).

Desse modo, o impacto financeiro do ICMS Verde paraense nos municípios prioritários contradiz a dupla dimensão da política e sua finalidade precípua de redução do desmatamento no estado, uma vez que tal grupo passou a receber maiores valores de repasse desde a sua introdução. Tal quadro pode ser explicado pela incapacidade dos indicadores que compõem o critério ecológico em mensurar o uso inadequado da floresta amazônica nos espaços territoriais especialmente protegidos e em assentamentos de reforma agrária, áreas sujeitas à ingerência do estado-membro e da União (FERREIRA, 2016).

É interessante verificar, porém, a possibilidade de valorização da finalidade do ICMS Ecológico paraense mesmo com o aumento de repasses financeiros a municípios desmatadores. Isso poderia se justificar na medida em que os municípios prioritários seriam aqueles onde mais se necessita incentivar o engajamento municipal no combate ao desmatamento, de modo que a transferência desses recursos seria grande arma utilizada para o fortalecimento da gestão ambiental municipal.

A fim de verificar tal hipótese, realizou-se análise da destinação orçamentária dos recursos geridos pelos municípios prioritários e de sua participação em ações de combate ao desmatamento. 


\section{DESTINAÇÃO DOS REPASSES FINANCEIROS E ENGAJAMENTO MUNICIPAL NO COMBATE AO DESMATAMENTO}

A Lei Estadual n. 7.638/2012 prevê, em seu art. 4 , que a destinação dos recursos oriundos do ICMS Verde a que cada município tiver direito será definida por legislação municipal, com ênfase na operacionalização do Fundo Municipal do Meio Ambiente e em sua gestão pelo Conselho Municipal do Meio Ambiente (PARÁ, 2012). Houve o intuito de que os valores repassados sob o critério ecológico fossem destinados ao financiamento das políticas ambientais municipais, de modo a possibilitar o exercício da autonomia local neste âmbito.

No entanto, tal dispositivo não deve ser interpretado como um comando vinculante em razão da restrição indevida da autonomia municipal que daí resultaria, bem como da vedação constitucional à vinculação da receita de impostos -, mas, sim, como uma norma programática, visto que propõe um objetivo a ser alcançado pela política, de forma não impositiva (TUPIASSU e HABER, 2014).

Conforme dados extraídos de relatórios do Programa Municípios Verdes (PMV), ${ }^{6}$ nenhum dos municípios prioritários, à exceção de Moju, regulamentou a destinação dos repasses oriundos do ICMS Verde (PMV, 2016a, 2017a, 2017b, 2017c, 2017d e 2017e). Contudo, o órgão ambiental desse município informou que, apesar disso, tais recursos não são transferidos ao Fundo Municipal do Meio Ambiente, o que contraria sua própria legislação municipal (PMV, 2017a).

Ressalte-se que a situação não se limita ao grupo de municípios analisados, visto que, dos 44 entes municipais monitorados até o momento pelo PMV, somente 4 têm alguma forma de regulamentação da destinação dos repasses recebidos sob o critério ecológico de repartição além de Moju, apenas os municípios de Brasil Novo, Paragominas e Bom Jesus do Tocantins (PMV, 2016a, 2017a, 2017b, 2017c, 2017d e 2017e). Logo, observa-se que, de modo geral, a aspiração do legislador estadual não se concretizou, visto que na maioria dos municípios paraenses - entre os quais, os municípios prioritários - não há correlação entre os recursos recebidos em razão do ICMS Verde e a operacionalização do Fundo Municipal.

Ante a impossibilidade de impor a vinculação das receitas transferidas sob o critério ecológico, a inércia legislativa dos municípios pode ser explicada pela preferência em alocar os recursos recebidos em áreas que representem necessidades consideradas imediatas pela administração municipal, como a cobertura de despesas correntes. Ademais, outra hipótese a ser

6 “O Programa Municípios Verdes (PMV) é um programa do Governo do Pará desenvolvido em parceria com municípios, sociedade civil, iniciativa privada, Ibama e Ministério Público Federal, com o objetivo de combater o desmatamento e fortalecer a produção rural sustentável por meio de ações estratégicas de ordenamento ambiental e fundiário e gestão ambiental, com foco em pactos locais, monitoramento do desmatamento, implantação do Cadastro Ambiental Rural (CAR) e estruturação da gestão municipal” (WHATELY e CAMPANILI, 2013, s/n). 
levantada é a de que os agentes políticos municipais teriam dificuldades em propor e manter uma política ambiental de longo prazo, em razão da alternância de poder inerente às instâncias políticas locais. ${ }^{7}$

Embora os municípios prioritários não tenham estabelecido, dentro de sua esfera exclusiva de competência, normas que regulem a destinação dos repasses oriundos do ICMS Verde, considerava-se, à época de introdução da política, que aumentariam seus investimentos com a gestão ambiental (TUPIASSU e OLIVEIRA, 2016), já que, em geral, a política possui a função de incentivar a adoção de condutas ambientalmente desejáveis pelos entes municipais e, no caso paraense, houve a intenção específica de incentivar a estruturação de um sistema de gestão ambiental municipal. De fato, um dos resultados esperados do ICMS Verde é o aumento das despesas dos municípios com a gestão ambiental, como já se verificou em outros estados, como no estado do Rio de Janeiro (FERREIRA et al., 2015).

Nesse sentido, realizou-se análise da evolução do percentual de despesas orçamentárias destes municípios alocado à função gestão ambiental, em período que compreende os quatro primeiros exercícios financeiros decorridos desde a introdução da política (2013-2016) e os quatro anteriores (2009-2012).

Ressalte-se que alguns dos municípios não figuram nas bases de dados referentes a um ou dois exercícios financeiros do período analisado ${ }^{8} \mathrm{e}$, em certos casos, embora o município conste da base de dados, não houve registro de despesas sob a função gestão ambiental. No primeiro caso, optou-se por excluir o exercício financeiro do cômputo, enquanto que, no segundo, considerou-se não ter ocorrido qualquer despesa nessa área no exercício financeiro. Os resultados encontram-se dispostos na Tabela 3.

7 A fim de atestar cientificamente quais critérios são determinantes para a ausência de destinação ambiental dos recursos recebidos a título de ICMS Verde, é necessário realizar-se larga pesquisa empírica, que supera os objetivos do presente estudo.

8 O município de Altamira não consta das bases de dados referentes aos anos de 2015 e 2016. Contudo, foi possível obter as informações destes exercícios financeiros a partir dos balanços orçamentários disponibilizados no sítio eletrônico da prefeitura municipal. 
tabela 3 - Percentual de deSPeSAS orÇAMENTÁrias Registradas Sob a FunÇÃo GESTÃO AMBIENTAL EM RELAÇÃO AOTOTAL DE DESPESAS NO EXERCÍCIO FINANCEIRO

\begin{tabular}{|c|c|c|c|c|c|c|c|c|}
\hline & 2009 & 2010 & 2011 & 2012 & 2013 & 2014 & 2015 & 2016 \\
\hline ALTAMIRA & 0,00 & 0,87 & 0,09 & - & 0,65 & 0,73 & 3,13 & 5,55 \\
\hline ANAPU & 0,01 & 0,41 & 0,00 & 0,00 & 0,81 & 0,86 & 0,84 & 0,78 \\
\hline CUMARU DO NORTE & 1,18 & 1,04 & 1,11 & 1,22 & 0,00 & - & 1,29 & - \\
\hline ITUPIRANGA & 0,00 & 0,21 & 0,31 & 0,00 & 0,37 & 0,00 & 0,00 & 0,00 \\
\hline MARABÁ & 0,99 & 1,00 & 1,56 & 1,22 & 0,41 & 0,37 & 0,39 & 0,40 \\
\hline MOJU & 0,19 & 0,53 & 0,34 & 0,32 & 0,01 & 0,32 & 0,44 & 0,67 \\
\hline NOVO PROGRESSO & 0,49 & 0,48 & 0,01 & 0,24 & 0,57 & 0,58 & 0,78 & 0,82 \\
\hline NOVO REPARTIMENTO & 0,02 & 0,01 & 0,01 & 0,45 & 0,64 & 3,40 & 3,57 & 3,09 \\
\hline PACAJÁ & 1,30 & 1,04 & 4,65 & 1,33 & 2,04 & 2,29 & 1,96 & 2,48 \\
\hline RONDON DO PARÁ & 0,71 & 0,45 & 0,22 & 0,32 & 0,42 & 0,31 & 0,32 & 0,29 \\
\hline SANTA MARIA DAS BARREIRAS & 0,00 & 0,00 & 0,00 & 0,00 & 0,00 & 0,00 & 0,00 & 0,01 \\
\hline SÃO FÉLIX DO XINGU & 1,97 & 2,61 & 0,37 & 0,17 & 0,33 & 0,57 & 1,84 & 1,41 \\
\hline SENADOR JOSÉ PORFÍRIO & 1,67 & 1,67 & 1,66 & - & 1,80 & 2,39 & 1,65 & 1,74 \\
\hline MÉDIA & 0,66 & 0,79 & 0,79 & 0,48 & 0,62 & 0,99 & 1,25 & 1,44 \\
\hline
\end{tabular}

Fonte: Elaboração dos autores com base em dados oficiais (BRASIL, 2009, 2010, 2012, 2014a, 2014 b e 2017c).

Ainda, comparou-se as médias de gastos proporcionais com a gestão ambiental no período anterior (2008-2012) e posterior (2013-2016) à Lei Estadual n. 7.638/2012. Optou-se por enquadrar o exercício financeiro de 2012 no período anterior à implementação da política, visto que a Lei Estadual n. 7.638/2012 somente foi promulgada em julho daquele ano, obtendo-se os dados constantes na Tabela 4. 
TABELA 4 - MÉdiA PERCENTUAL DE DESPESAS ORÇAMENTÁRIAS REGISTRADAS SOB A
FUNÇÃO GESTÃO AMBIENTAL NOS PERÍODOS 2008-20I 2 E $2013-20 I 6$

MÉDIA 2009-2012 MÉDIA 2013-2016 MÉDIA 2008-2016

\begin{tabular}{|c|c|c|c|}
\hline ALTAMIRA & 0,32 & $2,52(+)$ & 1,58 \\
\hline ANAPU & 0,11 & $0,82(+)$ & 0,46 \\
\hline CUMARU DO NORTE & 1,14 & $0,64(-)$ & 0,97 \\
\hline ITUPIRANGA & 0,13 & $0,09(-)$ & 0,11 \\
\hline MARABÁ & 1,19 & $0,39(-)$ & 0,79 \\
\hline MOJU & 0,35 & $0,36(-)$ & 0,35 \\
\hline NOVO PROGRESSO & 0,31 & $0,69(+)$ & 0,50 \\
\hline NOVO REPARTIMENTO & 0,12 & $2,67(+)$ & 1,40 \\
\hline PACAJÁ & 2,08 & $2,19(+)$ & 2,14 \\
\hline RONDON DO PARÁ & 0,43 & $0,34(-)$ & 0,38 \\
\hline SANTA MARIA DAS BARREIRAS & 0,00 & $0,00 l=1$ & 0,00 \\
\hline SÃO FÉLIX DO XINGU & 1,28 & $1,04(-)$ & 1,16 \\
\hline SENADOR JOSÉ PORFÍRIO & 1,67 & $1,89(+)$ & 1,80 \\
\hline MUNICÍPIOS PRIORITÁRIOS & 0,68 & $1,07(+)$ & 0,88 \\
\hline
\end{tabular}

Fonte: Elaboração dos autores com base em dados oficiais (BRASIL, 2009, 2010, 2012, 2014a, 2014 b e 2017 c).

Percebe-se que a média de despesas orçamentárias dos municípios prioritários com gestão ambiental aumentou consideravelmente desde a introdução do ICMS Verde, com variação positiva de 57,35\%. Entretanto, não houve uma tendência uniforme entre os integrantes do grupo analisado, visto que cinco dos doze municípios registraram reduções significativas de 
gastos dessa natureza e o município de Santa Maria das Barreiras não informou qualquer despesa, em ambos os períodos. Além disso, boa parte do crescimento se concentrou nos municípios de Altamira e Novo Repartimento, sendo que, quanto ao primeiro, parcela expressiva das despesas no ano de 2016 decorreu de modificação nos procedimentos contábeis da administração municipal. ${ }^{9}$

De qualquer modo, conquanto não exista regulamentação normativa acerca da destinação dos repasses provenientes do ICMS Verde e não se tenha constatado uma tendência uniforme de aumento de despesas com a gestão ambiental municipal, é certo que, quanto aos municípios prioritários, a política não surtiu a eficácia esperada de controle e redução do desmatamento, conforme acusam as taxas registradas nos últimos anos.

Como se depreende do Gráfico 3, desde a implementação da política, em 2012, a participação da taxa de incremento de desmatamento nos municípios prioritários em relação ao verificado em todo o estado manteve-se estável.

\section{GrÁfico 3 - TAXAS ANUAis de inCREMENTO de DeSMATAMENTO nO eSTAdo do ParÁ E NOS MUNICÍPIOS PRIORITÁRIOS, EM KM² DE ÁREA DESMATADA ( 20 I 2 - 2 o I 7 )}

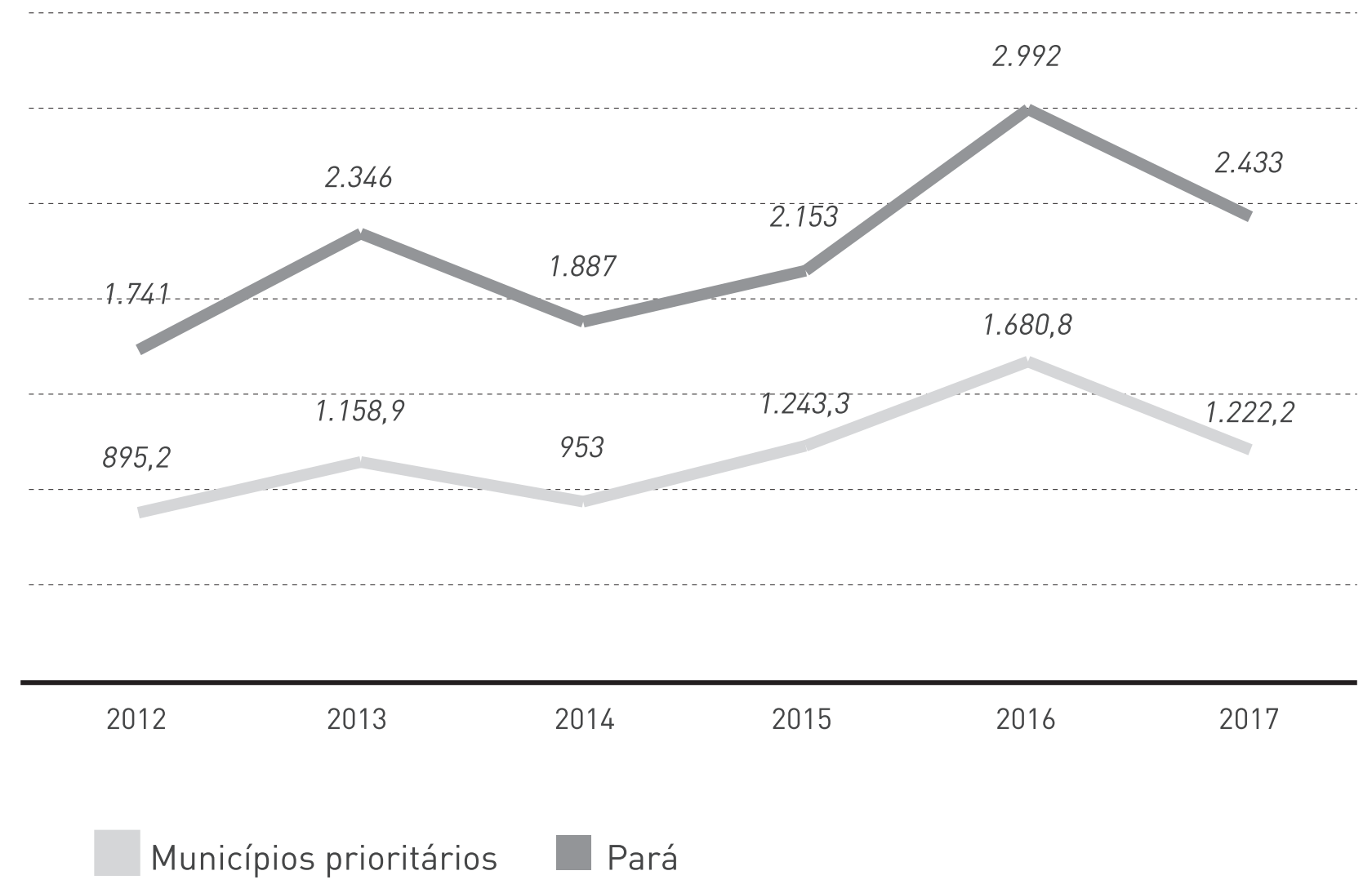

Fonte: Elaboração dos autores com base em dados oficiais (INPE, 2018).

9 Em 2016, do total de despesas registradas por Altamira como de gestão ambiental, quase metade decorreu da "manutenção de serviços de limpeza pública", gasto que até 2015 não era computado sob esta função (ALTAMIRA, 2015 e 2016). 
Em vista de seu objetivo central, esperava-se que a política fomentasse maior envolvimento dos municípios nas ações cooperadas de combate ao desmatamento, desenvolvidas em conjunto com outros entes federativos. No âmbito do PMV, tal pensamento está relacionado a algumas das metas a que os municípios se submetem ao aderir ao programa, como a de verificação em campo de focos de desmatamento, na qual os municípios devem atender a alertas emitidos em boletins mensais de monitoramento produzidos pelo Sistema de Alertas de Desmatamento (SAD), com posterior encaminhamento de relatórios à Semas/PA. ${ }^{10}$ Considera-se cumprida a meta quando o município responder a todos os alertas que receber ou caso não receba nenhum; se responder mais da metade dos alertas, a meta é considerada parcialmente cumprida.

Conforme relatórios desenvolvidos no âmbito do PMV, dos municípios prioritários, somente Senador José Porfírio respondeu a todos os alertas de desmatamento recebidos no ano de 2016 e, quanto aos demais, a realização de verificação em campo foi incipiente ou totalmente inexistente, à exceção de Rondon do Pará, conforme se percebe pela análise dos dados contidos na Tabela 5.

TABELA 5 - VERIFICAÇÃO EM CAMPO DE FOCOS DE DESMATAMENTO NOS MUNICÍPIOS PRIORITÁRIOS ( 20 I 6 )

\begin{tabular}{lllll} 
& $\begin{array}{l}\text { ALERTAS } \\
\text { RECEBIDOS - 2016 }\end{array}$ & $\begin{array}{l}\text { ALERTAS } \\
\text { RESPONDIDOS - 2016 }\end{array}$ & $\begin{array}{l}\text { ALERTAS NÃO } \\
\text { RESPONDIDOS - 2016 }\end{array}$ & $\begin{array}{l}\text { CUMPRIU A } \\
\text { META }\end{array}$ \\
\hline ALTAMIRA & 205 & 13 & 192 & NÃO \\
\hline ANAPU & 45 & 0 & 45 & NÃO \\
\hline CUMARU DO NORTE & 4 & 0 & 4 & NÃO \\
\hline ITUPIRANGA & 5 & 0 & 5 & NÃO
\end{tabular}

(continua)

10 "A partir do recebimento da informação, o município tem a missão de fiscalizar em campo para saber se o desmatamento de fato ocorreu e qual a sua finalidade (a atividade para a qual se destina). Para tanto, recebe um boletim de verificação em campo a ser preenchido pelo município e devolvido para o PMV. Esta é a prova documental, que deve conter fotos, detalhes de localização e motivos do desmatamento, e será usada para a responsabilização do infrator pelos órgãos competentes, como a Sema ou o MPF. É um instrumento para dar capacidade de resposta aos alertas de desmatamento" (WHATELY e CAMPANILI, 2013, p. 45-46). 


\begin{tabular}{|c|c|c|c|c|}
\hline & $\begin{array}{l}\text { ALERTAS } \\
\text { RECEBIDOS - } 2016\end{array}$ & $\begin{array}{l}\text { ALERTAS } \\
\text { RESPONDIDOS - } 2016\end{array}$ & $\begin{array}{l}\text { ALERTAS NÃO } \\
\text { RESPONDIDOS - } 2016\end{array}$ & $\begin{array}{l}\text { CUMPRIU A } \\
\text { META? }\end{array}$ \\
\hline MARABÁ & 20 & 4 & 16 & NÃO \\
\hline MOJU & 3 & 1 & 2 & NÃO \\
\hline NOVO PROGRESSO & 80 & 0 & 80 & NÃO \\
\hline NOVO REPARTIMENTO & 55 & 13 & 42 & NÃO \\
\hline PACAJÁ & 80 & 3 & 77 & NÃO \\
\hline RONDON DO PARÁ & 13 & 11 & 2 & PARCIALMENTE \\
\hline \multicolumn{5}{|l|}{ SANTA MARIA } \\
\hline DAS BARREIRAS & 1 & 0 & 1 & NÃO \\
\hline SÃO FÉLIX DO XINGU & 209 & 0 & 209 & NÃO \\
\hline SENADOR JOSÉ PORFÍRIO & 23 & 23 & 0 & SIM \\
\hline TOTAL & 743 & 68 & 675 & \\
\hline
\end{tabular}

Fonte: Elaboração dos autores com base em dados oficiais (PMV, 2017f, 2017g, 2017h, 2017i, $2017 \mathrm{j}$ e 2017k).

Outras metas do PMV diretamente relacionadas à busca de um engajamento maior dos municípios no combate ao desmatamento são as de celebrar pacto local de prevenção e combate ao desmatamento ilegal e promoção do desenvolvimento sustentável (meta I) e de constituir e funcionar grupo de trabalho municipal com a mesma finalidade (meta II). Tais objetivos foram estabelecidos com base na experiência do município de Paragominas, o qual conseguiu sair da Lista de Municípios Prioritários a partir da formação de amplas coalizões locais contra o desmatamento (WHATELY e CAMPANILI, 2013).

Todos os municípios prioritários celebraram o pacto local, atendendo à meta I do Programa. Entretanto, em relação à meta II, constata-se que, embora a maioria dos municípios tenha constituído o grupo de trabalho - à exceção de Novo Progresso, que não comprovou a formação do grupo -, seu funcionamento é, no melhor dos casos, incipiente. Durante o ano de 2016, nenhum dos municípios prioritários promoveu reuniões dos grupos (PMV, 
2017f, 2017g, 2017h, 2017i, 2017j e 2017k). Embora no primeiro trimestre de 2017 tenham ocorrido reuniões em alguns municípios, na maioria dos casos os grupos de trabalho não foram considerados ativos pelo Programa (PMV, 2017l, 2017m, 2017n, 2017o, 2017p, 2017q e 2017r).

Portanto, os dados acima expostos expõem uma situação contraditória em relação ao tratamento benéfico recebido pelos municípios prioritários desde a implementação do ICMS Verde. Ao contrário do que se tencionou com a edição da Lei Estadual n. 7.638/2012, de modo geral, os repasses oriundos do ICMS Verde não são destinados, por meio de regulamentação de lei municipal, aos Fundos Municipais. Ainda, embora tenha ocorrido um aumento na média de despesas com a gestão ambiental, a tendência não foi uniforme, visto que, em metade dos municípios analisados, houve redução ou ausência de despesas nesta função. Ademais, as taxas de incremento de desmatamento destes municípios não mostram sinais de arrefecimento, enquanto que não se constata um efetivo engajamento dos entes municipais em ações de combate ao desmatamento.

Uma hipótese para a ausência de engajamento em gestão ambiental - ou ausência de efeitos de tal engajamento - por parte dos municípios é de que tais entes sofrem limitações, fáticas e jurídicas à sua atuação em grande parcela de seu território, a qual se encontra sujeita a restrições impostas pelo estado e pela União. Em vista disso, como já observado, buscou-se analisar as possibilidades de atuação municipal em espaços territoriais sob influência estadual e federal, a partir do estudo de dois municípios prioritários do estado do Pará.

\section{Possibilidades de atuação dos municípios de Altamira e São Félix do XiNGU NO COMBATE AO DESMATAMENTO EM ESPAÇOS SOB GESTÃOTERRITORIAL E FISCALIZAÇÃO AMBIENTAL FEDERAL E ESTADUAL}

Altamira e São Félix do Xingu lideram, desde 2012, a lista dos municípios com as maiores taxas de incremento de desmatamento no Estado (INPE, 2017a) e, também, figuram como os maiores recebedores de repasses sob o ICMS Verde em 2017, segundo índices divulgados pela Semas/PA (PARÁ, 2017d).

A situação apresentada contradiz, como já visto, as diretrizes de compensação e incentivo inerentes ao ICMS Verde. A presença de áreas protegidas no município lhe permite auferir maiores receitas sob o critério ecológico, embora parcela significativa do incremento de desmatamento também se dê nesses espaços, produzindo externalidades negativas. A natureza predominantemente quantitativa dos indicadores ambientais utilizados torna invisível à política o processo agravado de degradação ambiental no qual se encontram, por exemplo, unidades de conservação situadas em frentes de avanço do desmatamento.

No entanto, considerada sua finalidade precípua de combater o desmatamento por meio de incentivos financeiros à contribuição dos entes municipais, a configuração do ICMS Verde deve levar em conta as possibilidades de contribuição dos municípios nessa tarefa, notadamente em 
áreas sujeitas à ingerência do estado-membro e da União, nas quais a atuação municipal pode enfrentar óbices de natureza jurídica e fática.

Em vista disso, realizou-se análise da dinâmica do desmatamento na parcela dos territórios de Altamira e São Félix do Xingu que se encontra sob a gestão territorial e fiscalização ambiental das esferas estadual e federal. Os municípios foram selecionados para exame conjunto por apresentarem as maiores taxas de desmatamento no estado e terem territórios contíguos, compartilhando espaços protegidos. Nesse ínterim, reuniram-se dados referentes ao desmatamento em unidades de conservação, terras indígenas, assentamentos de reforma agrária e glebas públicas federais situados nestes municípios, disponibilizados pelo Projeto Prodes, Instituto Socioambiental (ISA), MMA e PMV, buscando-se identificar as principais medidas de gestão ambiental adotadas e qual o papel dos municípios - bem como os óbices à sua atuação efetiva - no combate ao desmatamento nesses espaços.

Inicialmente, observa-se que 90,02\% do território de Altamira, e 74,42\% do de São Félix está tomado por áreas protegidas (ISA, 2017a). Das categorias de áreas protegidas encontradas nestes municípios, constata-se que o processo de desmatamento nas 11 terras indígenas (TIs) que perpassam seus territórios é o de menor expressão, chegando a pouco mais de 1\% do total desmatado entre 2012 e 2014 (ISA, 2017a). É um cenário esperado, visto que as terras indígenas constituem a categoria de área protegida mais eficaz em inibir o processo de desflorestamento e evitar as emissões associadas de gases do efeito estufa (SOARES-FILHO, 2010), o que se deve à existência de atributos ambientais que as diferenciam dos demais espaços protegidos - elas têm um regime jurídico peculiar, visto que servem como suporte da organização social e identidade cultural dos povos indígenas (BRITO e BARBOSA, 2015).

Os municípios analisados albergam, entre si, treze Unidades de Conservação (UCs), duas das quais de criação estadual (ambas de uso sustentável) e onze federais (quatro de proteção integral e sete de uso sustentável) (ISA, 2017b). Dentre as UCs, duas estão entre as dez mais desmatadas da Amazônia legal no período de 2012 a 2015: a primeira colocada, a Área de Proteção Ambiental (APA) Trunfo do Xingu e a sexta, a Floresta Nacional Altamira (ARAÚJJO, 2017). Somente nessa primeira UC, de criação estadual, situada no território de ambos os entes municipais, ocorreu aproximadamente 24,2\% do desmatamento registrado nos municípios no período. Entre 2012 e 2015, foram desmatados $1.868,90 \mathrm{~km}^{2}$ de floresta nos dois municípios, dos quais, 453,25 km² somente na APA Trunfo do Xingu (INPE, 2017a e 2017b).

Uma das principais causas de desmatamento na APA Triunfo do Xingu é a ocupação irregular de terras, decorrente da ausência de regularização fundiária e, sobretudo, de um plano de manejo, que delimite as áreas destinadas à preservação de recursos ambientais, insuscetíveis de ocupação. Além disso, a fiscalização de atividades poluidoras é precária, já que a equipe gestora da UC é composta por apenas quatro pessoas, também responsáveis pela gestão de outras quatro UCs (ARAÚJO et al., 2017). 
Como a APA Triunfo do Xingu foi criada em 2006, a elaboração de seu plano de manejo - tarefa de atribuição do órgão gestor estadual, o Ideflor-bio - deveria ter ocorrido até 2011, em razão do prazo de cinco anos estabelecido pela legislação (BRASIL, 2000). Logo, a inércia do poder público estadual é fator determinante do nível de desmatamento nesta UC. Trata-se de violação do dever fundamental do poder público de proteger o meio ambiente que pode ensejar a responsabilização da pessoa jurídica a quem incumbe a tarefa de elaborar o plano (MACHADO, 2013).

Além disso, a competência prevalente para o exercício do poder de polícia ambiental em UCs é atribuída pela Lei Complementar n. 140, de 8 de dezembro de 2011, ao seu órgão gestor. Embora a concessão de licenciamento ou autorização para supressão ou manejo de vegetação em APAs, quanto a atividades que causem ou possam causar impacto ambiental de âmbito local, seja atribuição dos entes municipais, a ausência de plano de manejo é bastante prejudicial, devido à incerteza jurídica causada pela inexistência de normas que regulem a ocupação e uso dos recursos naturais da área (BRASIL, 2011).

Quanto ao desmatamento em projetos de assentamento (PA), percebe-se que dois dos PAs com as maiores taxas de desmatamento entre 2012 e 2015 estão situados no município de Altamira: os Projetos de Desenvolvimento Sustentável (PDS) Terra Nossa e Itatá (BRASIL, 2016). Além disso, segundo apurado pelo PMV, cerca de 35,9\% do desmatamento registrado em São Félix do Xingu entre 2012 e 2014 ocorreu em PAs (PMV, 2016b).

Há, portanto, uma participação expressiva dos assentamentos na dinâmica do desmatamento desses municípios, a qual também se verifica na Amazônia como um todo - entre 2010 e 2014, 29,2\% do desmatamento amazônico se deu nessas áreas (ALENCAR et al., 2016). A carência de políticas públicas de apoio à produção sustentável, aliada à ocorrência de vetores diretos - como a utilização de pecuária extensiva -, são características prevalentes nos assentamentos com as maiores taxas de desmatamento. Nesse sentido, a redução do desmatamento depende de uma reestruturação institucional do Incra, para que se adéque ao desafio de promover a sustentabilidade econômica e ambiental nos assentamentos (ALENCAR et al., 2016). Ressalte-se ainda que a competência prevalente para fiscalizar assentamentos recai sobre os estados-membros, visto que lhes cabe aprovar o manejo e a supressão de vegetação em imóveis rurais (BRASIL, 2011).

Por fim, verifica-se que o município de Altamira abrange a gleba pública federal com o maior desmatamento entre 2012 e 2015 (Curuaes) e parte da segunda e terceira (Gorotire e Curuá) (BRASIL, 2016). Somente na primeira área, foram desmatados $394,36 \mathrm{~km}^{2}$ de floresta de 2012 a 2015, o que equivale a 34,9\% do desmatamento ocorrido no município, nesse período. A existência de efetiva governança fundiária é condição necessária para o combate ao desmatamento nestas áreas, as quais estão inseridas no programa Terra Legal do governo federal, que visa atingir a regularização fundiária mediante a concessão de direito real de uso aos posseiros legítimos de terras públicas federais não destinadas, de modo a promover modelos de produção sustentável (BRASIL, 2016). 
Vê-se, deste modo, que a efetividade do combate ao desmatamento nos municípios analisados depende de condutas de atribuição estadual e federal, como a promoção do ordenamento fundiário e territorial em UCs de uso sustentável e em terras públicas, bem como a adoção de políticas públicas de incentivo a modelos sustentáveis de produção em assentamentos de reforma agrária. Ademais, o exercício do poder de polícia ambiental em UCs e PAs cabe, segundo a Lei Complementar n. 140/2011, em primeiro lugar, ao ente instituidor e ao estado-membro, respectivamente.

Por outro lado, como o princípio da cooperação orienta a distribuição da competência material ambiental, todos os entes federativos possuem o dever fundamental de atuar de forma conjunta na defesa do meio ambiente. Desse modo, embora se reconheça as dificuldades dos entes municipais em contribuir para o combate ao desmatamento nas áreas em análise, não há como se afirmar que não possuem um papel a desempenhar nesta tarefa.

Observa-se que existem vozes críticas, que levantam dúvidas acerca da constitucionalidade de algumas disposições da Lei Complementar n. 140/2011, sobretudo em relação à previsão de um sistema único de licenciamento (MACHADO, 2013, p. 324) e à vinculação entre a competência de licenciar e de fiscalizar (ARAÚJO, 2013, p. 529-530). De qualquer modo, conquanto não caiba fazer maiores considerações acerca da constitucionalidade desta lei - por extrapolar o objeto de estudo -, percebe-se que os municípios podem contribuir, ainda que sob o marco da Lei Complementar n. 140/2011, para a fiscalização ambiental nas áreas em análise, como ocorre com a verificação em campo empreendida no âmbito do PMV - a qual está compreendida na previsão do $\S 2^{\circ}$ do art. 17 da lei complementar. ${ }^{11}$

Ademais, quanto ao desmatamento ocorrido em UCs, os governos e as comunidades locais podem contribuir para o exercício do poder de polícia em seu entorno, sobretudo na zona de amortecimento, caso já estabelecida pelo plano de manejo (NEVES, 2012). Ainda, a efetiva implementação de grupos de trabalho envolvendo atores locais - uma das metas do PMV que não foi atendida pela maioria dos municípios analisados, como visto acima - é outra medida que pode se mostrar eficaz no combate ao desmatamento nestas áreas.

O enfoque conferido à questão deve levar em consideração o dever fundamental de cooperação entre os entes federativos para a concretização do direito ao meio ambiente equilibrado e não somente a perspectiva da autonomia de cada ente. Não se pode esperar que os municípios atuem de forma preeminente, posto que não possuem as atribuições necessárias para tanto e a tarefa pode demandar capacidades e recursos que excedem as construídas até o momento - o que não implica, contudo, dizer não possam contribuir. É preciso que o estado-membro e a União criem políticas específicas para controlar e reduzir o desmatamento

"Nos casos de iminência ou ocorrência de degradação da qualidade ambiental, o ente federativo que tiver conhecimento do fato deverá determinar medidas para evitá-la, fazer cessá-la ou mitigá-la, comunicando imediatamente ao órgão competente para as providências cabíveis" (BRASIL, 2011). 
nestas áreas ou que forneçam maior apoio e busquem o fortalecimento das que já existem, ${ }^{12}$ especialmente por meio de estímulos à adesão dos governos locais.

O ICMS Verde pode constituir incentivo efetivo para a construção de capacidades e contribuição municipal ao combate ao desmatamento nestas áreas, e, ainda, induzir os governos locais a participar ativamente de políticas específicas de iniciativa estadual e federal. No entanto, o tratamento benéfico recebido pelos municípios prioritários até o momento, sem que se verifique o seu correspondente comprometimento com o objetivo central da política, pode prejudicar quaisquer dessas intenções.

\section{CONCLUSÃo}

O quadro evidenciado pelo presente estudo é de contrariedade, até o momento, entre a base teórica que informa o ICMS Verde paraense, bem como sua finalidade específica de controle do desmatamento, em relação aos resultados práticos alcançados desde a introdução da política. Os municípios prioritários - os quais deveriam, com fundamento nas diretrizes de compensação e incentivo, receber menores valores de repasse com a introdução do critério ecológico - saíram beneficiados com a implementação do ICMS Verde, sem que tenham apresentado maior engajamento no combate ao desmatamento ou maior direcionamento de recursos à gestão ambiental.

Como visto, os municípios analisados não destinam os valores recebidos em função do critério ecológico a seus fundos municipais de meio ambiente, tal qual tencionou o legislador estadual. Ademais, a observação das despesas orçamentárias desse grupo de municípios indicou que não houve uma tendência uniforme de aumento de gastos com gestão ambiental desde a introdução do ICMS Verde. O acréscimo verificado se concentrou em poucos municípios, e quase metade dos entes registrou diminuição da participação das despesas com gestão ambiental nos exercícios financeiros posteriores à implementação da política quanto ao total de despesas realizadas.

Ademais, os municípios prioritários não cumprem metas do PMV diretamente relacionadas à sua participação no combate ao desmatamento - como a verificação em campo de alertas de desmatamento e, sobretudo, a organização de pactos locais com entes da sociedade civil -, que o ICMS Verde busca incentivar. Além disso, embora os referidos municípios tenham recebido maiores valores de repasse desde a introdução do ICMS Verde, não houve diminuição em sua participação nas taxas de desmatamento verificadas no estado.

Portanto, o ICMS Verde recompensou os municípios em que ocorre a maior parte do desmatamento no estado - em contradição com as funções compensatória e incentivadora

Por exemplo, o Programa Assentamentos Verdes (PAV), lançado pelo Incra no final de 2012 com objetivo de tornar os assentamentos comunidades rurais mais autônomas e ambientalmente sustentáveis (ALENCAR et al., 2016). 
da política -, embora a sua atuação na defesa do meio ambiente tenha continuado a ser tímida. Uma alteração possível e já sugerida em outras pesquisas seria a adoção de modelos de indicadores multidimensionais adequados ao ecossistema amazônico, como o modelo Pressão- Estado-Resposta (PER), da Organização para Cooperação e Desenvolvimento Econômico (OCDE), e dos indicadores selecionados pelo Processo de Tarapoto (FERREIRA, 2016; NOBREGA, 2018).

Por outro lado, a efetividade da atuação municipal no combate ao desmatamento é limitada em áreas sob influência da União e do estado-membro, uma vez que depende da realização de condutas de atribuição da esfera estadual e federal, como o ordenamento territorial e a elaboração e aplicação efetiva do plano de manejo de UCs. Apesar disso, remanesce o dever fundamental de cooperação entre os entes federativos para a proteção do meio ambiente, bem como a possibilidade de atuação municipal por meio de outras medidas. As políticas ambientais nesses espaços devem ser específicas e delineadas de maneira cooperativa, de modo que contemplem a participação de todas as esferas político-administrativas.

Nesse ponto, o ICMS poderia incentivar os municípios prioritários a construir as capacidades necessárias à sua atuação contra o desmatamento nesses espaços e a participar de políticas específicas de iniciativa estadual e federal. Entretanto, tal oportunidade pode ser desperdiçada em razão do tratamento benéfico conferido a esses municípios, visto que não há incentivo para que adotem uma postura mais enérgica na defesa dos bens ambientais dessas áreas.

As possibilidades, fáticas e jurídicas, de atuação dos entes municipais no combate ao desmatamento amazônico ainda não foram devidamente perscrutadas, o que se evidencia pela escassa literatura acerca do assunto (NEVES e WHATELY, 2016). Há uma íntima ligação entre essa temática e o ICMS Verde, o que demanda o aprofundamento de estudos acerca da adequação das capacidades e recursos dos quais os municípios dispõem atualmente para o exercício de sua autonomia local no que diz respeito a suas competências ambientais.

Com efeito, há uma premente necessidade de se realizar constante reavaliação dos instrumentos utilizados no contexto amazônico para a consecução do direito fundamental ao meio ambiente saudável, sobretudo ante às persistentemente altas taxas de desmatamento na região e no estado do Pará. Nesse sentido, relevantes são os resultados alcançados com a presente pesquisa, que reuniu e analisou informações suficientes para a realização de diagnóstico da política em relação ao grupo de municípios analisado, avaliando sua consonância com os objetivos por ela almejados. A discussão de tais resultados deve, portanto, contribuir para a realização das necessárias alterações da política pelo poder público estadual. 


\section{AGRADECIMENTOS}

Os autores agradecem ao financiamento do Conselho Nacional de Desenvolvimento Científico e Tecnológico (CNPq), da Coordenação de Aperfeiçoamento de Pessoal de Nível Superior, no âmbito do Programa Capes/Cofecub e da Agence Nationale de la Recherche no programa «Investissements d'avenir» (Ceba, réf. ANR-10-LABX-25-01).

\section{REFERÊNCIAS}

ALENCAR, Ane et al. Desmatamento nos assentamentos da Amazônia: histórico, tendências e oportunidades. Brasília, DF: IPAM, 2016.93 p. Disponível em: http:/ /ipam.org.br/wp-content/uploads/2016/02/ Desmatamento-nos-Assentamentos-da-Amaz\%C3\%B4nia.pdf. Acesso em: 20 maio 2019.

ALTAMIRA (Município). Balanço geral orçamentário do exercício financeiro de 2015. 2015. Disponível em: http:/ / altamira.pa.gov.br/site/wp-lincontent/uploads/2017/03/Balan\%C3\%A7o-Geral-2015.pdf. Acesso em: 15 jun. 2017.

ALTAMIRA (Município). Balanço geral orçamentário do exercício financeiro de 2016. 2016. Disponível em: http:/ / altamira.pa.gov.br/site/wp-content/uploads/2017/04/Balan\%C3\%A7o-Geral-2016. pdf. Acesso em: 15 jun. 2017.

ARAÚJO, Elis et al. Unidades de conservação mais desmatadas da Amazônia Legal (2012-2015). Belém: Imazon, 2017. Disponível em: http: / /imazon.org.br/PDFimazon/Portugues/livros/UCS\%20mais\%20desmatadas \%20Amazonia_2012-2015.pdf. Acesso em: 15 jun. 2017.

ARAÚJO, Sarah Carneiro. Competência em matéria de licenciamento ambiental: do conflito à solução? Revista da Faculdade de Direito da Universidade Federal do Ceará, Fortaleza, v. 34, n. 1, p. 499 538, jan./jun. 2013.

BARDE, Jean-Philippe. Économie et politique de l'environnement. 2 ed. Paris: PUF, 1992.

BAUMOL, William J.; OATES, Wallace E. The theory of environmental policy. Cambridge: Cambridge University Press, 1988. 
BRASIL. Constituição Federal de 1988. Promulgada em 5 de outubro de 1988. Disponível em: http:// www.planalto.gov.br/ccivil_03/constituicao/constituicao.htm. Acesso em 15 jun. 2017.

BRASIL. Lei n. 9.985, de 18 de julho de 2000. Regulamenta o art. 225, § 1o, incisos I, II, III e VII da Constituição Federal, institui o Sistema Nacional de Unidades de Conservação da Natureza e dá outras providências. Disponível em: http://www.planalto.gov.br/ccivil_03/leis/19985.htm. Acesso em: 15 jun. 2017.

BRASIL. Ministério da Fazenda. Secretaria do Tesouro Nacional. Finanças do Brasil. Dados Contábeis dos Municípios, 2008. Brasília, DF: Ministério da Fazenda, 2009. v. LIV. Disponível em: http: / /www.tesouro. fazenda.gov.br/documents/10180/327844/pge_finbra_2008.zip/91ba191d-ee56-4a9e-90649c9583d4c67d. Acesso em 15 jun. 2017.

BRASIL. Ministério da Fazenda. Secretaria do Tesouro Nacional. Finanças do Brasil. Dados Contábeis dos Municípios, ano 2009. Brasília, DF: Ministério da Fazenda, 2010. v. LV. Disponível em: http: / /www. tesouro.fazenda.gov.br/documents/10180/327844/pge_finbra_2009.zip/8f85ed32-7a52-47dc-a7bae5ecaa551899. Acesso em 15 jun. 2017.

BRASIL. Lei complementar n. 140 de 8 de dezembro de 2011. Fixa normas, nos termos dos incisos III, VI e VII do caput e do parágrafo único do art. 23 da Constituição Federal, para a cooperação entre a União, os Estados, o Distrito Federal e os Municípios nas ações administrativas decorrentes do exercício da competência comum relativas à proteção das paisagens naturais notáveis, à proteção do meio ambiente, ao combate à poluição em qualquer de suas formas e à preservação das florestas, da fauna e da flora; e altera a Lei n. 6.938, de 31 de agosto de 1981.2011. Disponível em: http://www.planalto.gov.br/ccivil_03/leis/LCP/Lcp140.htm. Acesso em: 15 jun. 2017.

BRASIL. Ministério da Fazenda. Secretaria do Tesouro Nacional. Finanças do Brasil. Dados Contábeis dos Municípios, ano 2010. Brasília, DF: Ministério da Fazenda, 2012. v. LVI. Disponível em: http: / / www. tesouro.fazenda.gov.br/documents/10180/327844/pge_finbra_2010.zip/4560c066-10a1-483c-90677f1bb60b4152. Acesso em: 15 jun. 2017.

BRASIL. Ministério da Fazenda. Secretaria do Tesouro Nacional. Finanças do Brasil. Dados Contábeis dos Municípios, ano 2011. Vol. LVII. Brasília, DF: Ministério da Fazenda, 2014a. Disponível em: http://www.tesouro.fazenda.gov.br/documents/10180/327844/pge_finbra_2011.zip/0727964505d4-4835-9d59-b931f7144b0c. Acesso em: 15 jun. 2017.

BRASIL. Ministério da Fazenda. Secretaria do Tesouro Nacional. Finanças do Brasil. Dados Contábeis dos Municípios, ano 2012. Brasília, DF: Ministério da Fazenda, 2014b. v. LVIII. Disponível em: http: / / www.tesouro.fazenda.gov.br/documents/10180/327844/pge_finbra_2012.zip/561d62f0-caa9-4fe2b901-911f7e41b8d8. Acesso em: 15 jun. 2017. 
BRASIL. Ministério do Meio Ambiente e Sustentabilidade. Relatório de balanço da $3^{a}$ fase do PPCDAM (versão preliminar). 2016. Disponível em: http: / /www.mma.gov.br/images/arquivo/80120/PPCDAm\%203\% 20fase_Balanco_versao\%20BETA.pdf. Acesso em: 15 jun. 2017.

BRASIL. Ministério do Meio Ambiente. Plano de Prevenção e Controle do Desmatamento na Amazônia Legal, 2017a. Disponível em: https://www.mma.gov.br/component/k2/item/616-preven\%C3\%A7\%C3\% A3o-e-controle-do-desmatamento-na-amaz\%C3\%B4nia. Acesso em: 15 jun. 2017.

BRASIL. Ministério do Meio Ambiente. Lista de Municípios Prioritários da Amazônia, 2017b. Disponível em: http: / / www.mma.gov.br/images/arquivos/florestas/controle_e_prevencao/2014/lista_\%20 municipios_\%20prioritarios_07.08.pdf. Acesso em: 20 maio 2019.

BRASIL. Ministério da Fazenda. Secretaria do Tesouro Nacional. Sistema de Informações Contábeis e Fiscais do Setor Público Brasileiro. Contas Anuais (2013-2017). Brasília, DF: Ministério da Fazenda, 2017c. Disponível em: https://siconfi.tesouro.gov.br/siconfi/pages/public/consulta_finbra/finbra_list.jsf. Acesso em: 15 jun. 2017.

BRITO, Adam Luiz Claudino de; BARBOSA, Erivaldo Moreira. A gestão ambiental das terras indígenas e de seus recursos naturais: fundamentos jurídicos, limites e desafios. Veredas do Direito, Belo Horizonte, v. 12, n. 24, p. 97-123, jul./dez. 2015.

CONTI, José Maurício. Federalismo fiscal e fundos de participação. São Paulo: Juarez de Oliveira, 2001.

FERREIRA, Luciano Cavalcante de Souza. ICMSVERDE: um estudo sobre a adequação de seus indicadores à sustentabilidade amazônica. 2016. Dissertação (Mestrado em Direito, Políticas Públicas e Desenvolvimento Regional) - Centro Universitário do Estado do Pará, Belém, 2016.

FERREIRA, Simone Assis et al. Impacto do ICMS ecológico nos investimentos em saneamento e gestão ambiental: análise dos municípios do Estado do Rio de Janeiro. Revista de Gestão Ambiental e Sustentabilidade, São Paulo, v. 4, n. 2, maio/ago., 2015.

INSTITUTO NACIONAL DE PESQUISAS ESPACIAIS (INPE). Prodes - Desmatamento nos municípios. 2017a. Disponível em: http://www.dpi.inpe.br/prodesdigital/prodesmunicipal.php. Acesso em: 15 jun. 2017.

INSTITUTO NACIONAL DE PESQUISAS ESPACIAIS (INPE). Prodes - Desmatamento nas unidades de conservação. 2017b. Disponível em: http:/ / www.dpi.inpe.br/prodesdigital/prodesuc.php. Acesso em: 15 jun. 2017. 
INSTITUTO NACIONAL DE PESQUISAS ESPACIAIS (INPE). Prodes municipal. 2018. Disponível em: http://www.dpi.inpe.br/prodesdigital/prodesmunicipal.php. Acesso em: 11 jun. 2018.

INSTITUTO SOCIOAMBIENTAL (ISA). Terras indígenas no Brasil. 2017a. Disponível em: https:// terrasindigenas.org.br. Acesso em: 15 jun. 2017.

INSTITUTO SOCIOAMBIENTAL (ISA). Unidades de Conservação no Brasil. 2017b. Disponível em: https://uc.socioambiental.org/. Acesso em: 15 jun. 2017.

LÉVÊQUE, François. Externalities, collective goods and the requirement of a state's intervention in pollution abatement. In: LÉVÊQUE, Francois; CARRARO, Carlo. Voluntary approaches in environmental policy. Dordrecht: Springer Netherlands, 1999.

LOUREIRO, Wilson. Contribuição do ICMS Ecológico à conservação da biodiversidade no estado do Paraná. 2002. Tese (Doutorado em Engenharia Florestal) - Universidade Federal do Paraná, Curitiba, 2002.

MACHADO, Paulo Affonso Leme. Direito ambiental brasileiro. 21. ed. São Paulo: Malheiros, 2013.

MARSHALL, Alfred. Principles of economics. London: Macmillan and Co., 1920.

MILARÉ, Edis. Direito do ambiente. 10. ed. São Paulo: Revista dos Tribunais, 2015.

NEVES, Estela Maria Souza Costa et al. O processo de municipalização da estratégia de prevenção e combate ao desmatamento na Amazônia: estudos de casos sobre municípios integrantes da Lista de Municípios Prioritários do Ministério do Meio Ambiente, 2015. Disponível em: http: / www.municipiosverdes. pa.gov.br/files/999816d7a617e650c796109566e1337c/3def184ad8f4755ff269862ea77393dd/Estud o_\%20Processo\%20de\%20municipaliza \%C3\%A7ao\%20combate\%20ao\%20desmatamento\%20na\%2 0Amazonia.pdf. Acesso em: 02 set. 2019.

NEVES, Estela Maria Souza Costa. Política ambiental, municípios e cooperação intergovernamental no Brasil. Estudos Avançados, São Paulo, n. 74, p. 137-150, 2012.

NEVES, Estela Maria Souza Costa. Política e gestão no contexto municipal. Cadernos Adenauer, Rio de Janeiro, n. 2, p. 23-40, 2014.

NEVES, Estela Maria Souza Costa;WHATELY, Marussia. Municipalities and policies against deforestation in the Brazilian Amazon. Novos Estudos, Cebrap, São Paulo, v. 35, p. 67-83, nov. 2016. 
NOBREGA, Bernardo Mendonça. O ICMS Verde como instrumento de equidade intraestadual no Pará. 2018. Dissertação (Mestrado em Direito, Políticas Públicas e Desenvolvimento Regional) - Centro Universitário do Estado do Pará, Belém, 2018.

OLIVEIRA, Adriano Carvalho. ICMS ecológico e desenvolvimento: análise dos Estados de Rondônia, Tocantins, Ceará e Pará. 2014. Dissertação (Mestrado em Direito, Políticas Públicas e Desenvolvimento Regional) - Centro Universitário do Estado do Pará, Belém, 2014.

ORGANISATION DE COOPERATION ET DE DEVELOPPEMENT ÉCONOMIQUES (OCDE). Recommendation of the Council on Guiding Principles Concerning International Economic Aspects of Environmental Policies. Paris: OCDE, 1972.

ORGANISATION DE COOPERATION ET DE DEVELOPPEMENT ÉCONOMIQUES (OCDE). Instruments économiques pour la protection de l'environnement. Paris: OCDE, 1989.

PARÁ. Constituição do Estado do Pará. Promulgada em 5 de outubro de 1989. 1989.

PARÁ. Decreto Estadual n. 1.697, de 5 de junho de 2009. Institui o Plano de Prevenção, Controle e Alternativas ao Desmatamento do Estado do Pará, e dá outras providências. 2009. Disponível em: https: / /www.semas. pa.gov.br/2009/06/05/9701/. Acesso em: 15 jun. 2017.

PARÁ. Lei n. 7.638, de julho de 2012. Dispõe sobre o tratamento especial de que trata o $\S 2^{\circ}$ do art. 225 da Constituição do Estado do Pará. 2012. Disponível em: https: / /www.semas.pa.gov.br/wp-content/uploads/ 2015/11/legislacao/estadual/Lei_Estadual_no_7.638_ICMS_VERDE.pdf. Acesso em: 20 maio 2019.

PARÁ. Decreto n. 775, de 26 de junho de 2013. Regulamenta a Lei Estadual n. 7.638, de 12 de julho de 2012. 2013. Disponível em: https://www.semas.pa.gov.br/2013/06/27/d-e-c-r-e-t-o-no-775-de26-de-junho-de-2013-publicado-no-doe-no-32-426-de-27062013. Acesso em: 15 jun. 2017.

PARÁ. Secretaria de Estado de Meio Ambiente e Sustentabilidade. Diretrizes metodológicas e detalhamento dos critérios de repasse do ICMS Verde no estado do Pará: porção municipal. 2016. Disponível em: https:// www.semas.pa.gov.br/wp-content/uploads/2016/05/NOVA_METODOLOGIA_1.pdf. Acesso em: 15 jun. 2017.

PARÁ. Secretaria de Estado de Meio Ambiente e Sustentabilidade. Portaria Semas/PA n. 1.310 de 3 de agosto de 2017. Publica os dados, informações e índices definitivos referentes ao repasse do ICMS Verde aos municípios e dá outras providências. 2017. Disponível em: https: / /www.semas.pa.gov.br/2017/ 08/07/portaria-n1310-de-0382017-publicada-no-doe-n33432-de-7817-pag-38-e-39. Acesso em: 15 jun. 2017. 
PIGOU, Arthur Cecil. The economics of welfare. London: Macmillan and Co, 1929.

PROGRAMA MUNICÍPIOS VERDES (PMV). Diagnóstico da gestão ambiental municipal nos municípios vinculados à base local Dom Eliseu. 2016a. Disponível em: http://www.municipiosverdes.pa.gov.br/files/ edital/NEPMV_P7_Diag_Gest_Amb_Base\%20Local\%20Dom\%20Eliseu_revfinal.pdf. Acesso em: 15 jun. 2017.

PROGRAMA MUNICÍPIOS VERDES (PMV). Diagnóstico da dinâmica do desmatamento nos municípios da base local Redenção. 2016b. Disponível em http://www.municipiosverdes.pa.gov.br/files/edital/ NEPMV_P05_Diagno\%CC\%81stico\%20da\%20dina\%CC\%82mica\%20do\%20desmatamento_Base\% 20Local\%20Redenc\%CC\%A7a\%CC\%83o_v007.pdf. Acesso em 15 jun. 2017.

PROGRAMA MUNICÍPIOS VERDES (PMV). Diagnóstico da gestão ambiental municipal nos municípios vinculados à base local Altamira. 2017a. Disponível em: http: / / www.municipiosverdes.pa.gov.br/files / edital/NEPMV_P07_Diag_Ges_Amb_Geral_B_Altamira_rev-final.pdf. Acesso em: 15 jun. 2017.

PROGRAMA MUNICÍPIOS VERDES (PMV). Diagnóstico da gestão ambiental municipal nos municípios vinculados à base local Itaituba. 2017b. Disponível em: http: / /www.municipiosverdes.pa.gov.br/files / edital/NEPMV_P07_Diag_Ges_Amb_Geral_B_Itaituba_rev\%20final.pdf. Acesso em: 15 jun. 2017.

PROGRAMA MUNICÍPIOS VERDES (PMV). Diagnóstico da gestão ambiental municipal nos municípios vinculados à base local Marabá. 2017c. Disponível em: http: / /www.municipiosverdes.pa.gov.br/files / edital/NEPMV_P07_Diag_Ges_Amb_Geral_B_Maraba\%CC\%81_rev\%20final.pdf. Acesso em: 15 jun. 2017.

PROGRAMA MUNICÍPIOS VERDES (PMV). Diagnóstico da gestão ambiental municipal nos municípios vinculados à base local Redenção. 2017d. Disponível em: http: / /www.municipiosverdes.pa.gov.br/ files/edital/NEPMV_P07_Diag_Ges_Amb_Geral_B_Redencao_rev_final.pdf. Acesso em: 15 jun. 2017.

PROGRAMA MUNICÍPIOS VERDES (PMV). Diagnóstico da gestão ambiental municipal nos municípios vinculados à base local Tailândia. 2017e. Disponível em: http: / / www.municipiosverdes.pa.gov.br/files / edital/NEPMV_P07_Diag_Ges_Amb_Geral_B_Tailandia_rev\%20final.pdf. Acesso em: 15 jun. 2017.

PROGRAMA MUNICÍPIOS VERDES (PMV). Segundo relatório de monitoramento das ações do PMV nos municípios vinculados à base local Altamira. 2017f. Disponível em: http: / www.municipiosverdes.pa.gov.br / files/edital/P10.2_Rel_Monit_Altamira_NEPMV_10_2015_rev_02.pdf. Acesso em: 15 jun. 2017.

PROGRAMA MUNICÍPIOS VERDES (PMV). Segundo relatório de monitoramento das ações do PMV nos municípios vinculados à base local Dom Eliseu. 2017g. Disponível em: http: / / www.municipiosverdes. 
pa.gov.br/files/edital/P10\%202_Rel_Monit_DomEliseu_NEPMV_10_2015_rev_final.pdf. Acesso em: 15 jun. 2017.

PROGRAMA MUNICÍPIOS VERDES (PMV). Segundo relatório de monitoramento das ações do PMV nos municípios vinculados à base local Itaituba. 2017h. Disponível em: http: / / www.municipiosverdes.pa. gov.br/files/edital/P10\%202_Rel_Monit_Itaituba_NEPMV_10_2015_rev_final.pdf. Acesso em: 15 jun. 2017.

PROGRAMA MUNICÍPIOS VERDES (PMV). Segundo relatório de monitoramento das ações do PMV nos municípios vinculados à base local Marabá. 2017i. Disponível em: http: / / www.municipiosverdes.pa.gov.br/ files/edital/P10\%202_Rel_Monit_Maraba_NEPMV_10_2015_rev_final.pdf. Acesso em: 15 jun. 2017.

PROGRAMA MUNICÍPIOS VERDES (PMV). Segundo relatório de monitoramento das ações do PMV nos municípios vinculados à base local Redenção. 2017j. Disponível em: http://www.municipiosverdes.pa. gov.br/files/edital/P10\%202_Rel_Monit_Redencao_NEPMV_10_2015_rev_final.pdf. Acesso em: 15 jun. 2017.

PROGRAMA MUNICÍPIOS VERDES (PMV). Segundo relatório de monitoramento das ações do PMV nos municípios vinculados à base local Tailândia. 2017k. Disponível em: http://www.municipiosverdes. pa.gov.br/files/edital/P10\%202_Rel_Monit_Tailandia_NEPMV_10_2015_rev_final.pdf. Acesso em: 15 jun. 2017.

PROGRAMA MUNICÍPIOS VERDES (PMV). Terceiro relatório de monitoramento das ações do PMV nos municípios vinculados à base local Altamira. 2017l. Disponível em: http: / /www.municipiosverdes.pa.gov.br / files/edital/P10\%203_Rel_Monit_Altamira_NEPMV_10_2015_rev_02.pdf. Acesso em: 15 ago. 2017.

PROGRAMA MUNICÍPIOS VERDES (PMV). Terceiro relatório de monitoramento das ações do PMV nos municípios vinculados à base local Dom Eliseu. 2017m. Disponível em: http://www.municipiosverdes. pa.gov.br/files/edital/P10\%203_Rel_Monit_DomEliseu_NEPMV_10_2015_rev_02.pdf. Acesso em: 15 ago. 2017.

PROGRAMA MUNICÍPIOS VERDES (PMV). Terceiro relatório de monitoramento das ações do PMV nos municípios vinculados à base local Itaituba. 2017n. Disponível em: http: / www.municipiosverdes.pa.gov.br/ files/edital/P10\%203_Rel_Monit_Itaituba_NEPMV_10_2015_rev_02.pdf. Acesso em: 15 ago. 2017.

PROGRAMA MUNICÍPIOS VERDES (PMV). Terceiro relatório de monitoramento das ações do PMV nos municípios vinculados à base local Marabá. 2017o. Disponível em: http: / /www.municipiosverdes.pa.gov.br / files/edital/P10\%203_Rel_Monit_Maraba_NEPMV_10_2015_rev_02.pdf. Acesso em: 15 ago. 2017. 
PROGRAMA MUNICÍPIOS VERDES (PMV). Terceiro relatório de monitoramento das ações do PMV nos municípios vinculados à base local Redenção. 2017p. Disponível em: http: / /www.municipiosverdes.pa.gov.br / files/edital/P10\%203_Rel_Monit_Redencao_NEPMV_10_2015_rev_02.pdf. Acesso em: 15 ago. 2017.

PROGRAMA MUNICÍPIOS VERDES (PMV). Terceiro relatório de monitoramento das ações do PMV nos municípios vinculados à base local Tailândia. 2017q. Disponível em: http: / / www.municipiosverdes.pa. gov.br/files/edital/P10\%203_Rel_Monit_Tailandia_NEPMV_10_2015_rev_02.pdf. Acesso em: 15 ago. 2017.

PROGRAMA MUNICÍPIOS VERDES (PMV). Relatórios por município. 2017r. Disponível em: http: / /www. municipiosverdes.pa.gov.br/relatorios/seleciona_territorio/ficha_completa. Acesso em: 15 ago. 2017.

SARLET, Ingo Wolfgang; MACHADO, Paulo Affonso Leme; FENSTERSEIFER, Tiago. Constituição e legislação ambiental comentadas. São Paulo: Saraiva, 2015.

SCAFF, Fernando Facury; TUPIASSU, Lise Vieira da Costa. Tributação e políticas públicas: o ICMS ecológico. Verba Juris, João Pessoa, v. 3, n. 3, p. 154-190, jan./dez. 2004.

SOARES-FILHO, Britaldo et al. Role of Brazilian Amazon protected areas in climate change mitigation. PNAS 2010. 2010. Disponível em: http://www.pnas.org/content/107/24/10821.full.pdf. Acesso em: 15 jun. 2017.

TORRES, Ricardo Lobo. Tratado de Direito Constitucional Financeiro e Tributário: os Direitos Humanos e a Tributação. Rio de Janeiro: Renovar, 2005. v. III.

TUPIASSU, Lise Vieira da Costa. Tributação ambiental: a utilização de instrumentos econômicos e fiscais da implementação do direito ao meio ambiente saudável. Rio de Janeiro: Renovar, 2006.

TUPIASSU, Lise Vieira da Costa. Desenvolvimento econômico sustentável e tributação ambiental: breves fundamentos e perspectivas de estudo. In: DIAS, Jean Carlos; KLAUTAU FILHO, Paulo (coords.). Direitos fundamentais, teoria do direito e sustentabilidade. São Paulo: Método; Belém: Ed. CESUPA, 2010, p. 107-126.

TUPIASSU, Lise Vieira da Costa; HABER, Lilian Mendes. Quota-parte do ICMS e desenvolvimento sustentável: a nova Lei do ICMS Ecológico no estado do Pará. In: DIAS, Jean Carlos; GOMES, Marcus Alan de Melo. Direito e desenvolvimento. São Paulo: Método, 2014. p. 295-312.

TUPIASSU, Lise Vieira da Costa; OLIVEIRA, Adriano Carvalho. ICMSVerde para a redução do desmatamento amazônico: estudo sobre uma experiência recente. Veredas do Direito, Belo Horizonte, v. 13, n. 25, p. 277 306, 2016. 
TUPIASSU, Lise Vieira da Costa; GROS-DÉSORMEAUX, Jean-Raphaël; FADEL, Luiz Paulo de Sousa Leão. O impacto do ICMS Verde nos municípios prioritários do estado do Pará. Revista de Estudos Empíricos em Direito, São Paulo, v. 5, n. 2, p. 67-86, 2018.

WHATELY, Marussia; CAMPANILI, Maura (orgs.). Programa MunicípiosVerdes: lições aprendidas e desafios para 2013/2014. Belém/PA, 2013. Disponível em: http:/ /www.municipiosverdes.pa.gov.br/files / 999816d7a617e650c796109566e1337c/d67d8ab4f4c10bf22aa353e27879133c/PMV_Li\%C3\%A7\% C3\%B5es\%20Aprendidas\%20e\%20desafios\%20para\%202013_2014.pdf. Acesso em: 20 maio 2019.

WUNDER, Sven. Payments for environmental services: Some nuts and bolts. Occasional Paper, n. 42. Bogor: Center for International Forestry Research, 2005.

\section{COMO CITAR ESTE ARTIGO:}

TUPIASSU, Lise; FADEL, Luiz Paulo de Sousa Leão; GROS-DÉSORMEAUX, Jean-Raphaël. ICMS Ecológico e desmatamento nos municípios prioritários do Estado do Pará. Revista Direito GV, v. 15, n. 3, 2019, e1928. doi: http://dx.doi.org/10.1590/23176172201928.
Lise Tupiassu

Doutora em Direito PEla Université Toulouse 1 - CAPItOle. Mestre em Direito Tributário pela Université Paris I, Pantheon-Sorbonne. Mestre em Instituições Jurídico-Políticas pela Universidade Federal do Pará (UFPA). Mestre em Direito Público pela Université de Toulouse I - Capitole. Professora da Universidade Federal do Pará (UFPA) e do Centro Universitário do Estado do Pará (CESuPA). Cocoordenadora da Rede de Pesquisas Junction Amazonian Biodiversity Units Research Networking Program (Jambu RNP) e dos Grupos de Pesquisa (CNPQ) "BIOdiversidade, Sociedade e Território na Amazônia - BEST AmazônIA" E “Tributação Ambiental e Desenvolvimento".

liselaufpa.br

\section{Luiz Paulo de Sousa Leão Fadel}

Bacharel em Direito pela Universidade Federal do Pará. EX-BOLSISTA DE INICIAÇÃO CIENTÍFICA DO PROGRAMA $\mathrm{PIBIC/CNPQ/UFPA.}$

luizpfadelagmail.com

\section{Jean-Raphä̈l Gros-Désormeaux}

Doutor em Geografia pela Université des Antilles et de LA Guyanne (UAG). Pesquisador do Centre National des ReCherches Scientiques (CNRS) e do Laboratoire Caribéen de Sciences Sociales (LC2S). Co-coordenador da Rede de Pesquisas Junction AmaZONian BiOdiversity Units Research Networking Program (Jambu RNP). jrmgrosdesormeauxlayahoo.fr 